\title{
EFFECTS OF HEALTH INFORMATION SEEKING BEHAVIORS ON ANXIETY, AND LOSS \\ AMONG EAST ASIAN INTERNATIONAL STUDENTS
}

A Dissertation
presented to
the Faculty of the Graduate School
at the University of Missouri
In Partial Fulfillment
of the Requirements of the
Degree Doctor of Philosophy
CHIH-CHUN CHUANG

Dr. Alex Waigandt, Dissertation Supervisor

July 2017 
(C) Copyright by Chih-Chun Chuang 2017 All Rights Reserved 
The undersigned, appointed by the dean of the Graduate School, have examined the dissertation entitled

\section{EFFECTS OF HEALTH INFORMATION SEEKING BEHAVIORS \\ ON ANXIETY, AND LOSS AMONG EAST ASIAN INTERNATIONAL STUDENTS}

Presented by Chih-Chun Chuang,

A candidate for the degree of Doctor of Philosophy,

And hereby certify that, in their opinion, it is worthy of acceptance.

Dr. Alex Waigandt

Dr. Kenneth T. Wang

Dr. Sonia Dhaliwal

Dr. Rachel J. Pinnow 


\section{ACKNOWLEDGEMENT}

Coming to the end of a long journey, I have never encountered so many challenges in throughout my entire academic life. Completing the dissertation and the final milestone of my doctoral degree has been a period of intense learning for me, not only in my own academic discipline but also on a personal level. I would like to take a moment to reflect and say thank you to the people who have supported and helped me during this period of my life. I could not have accomplished this without their help and support.

I would like to extend my sincerest appreciation to my chair, Dr. Alex Waigandt, as well as all my committee members, Dr. Kenneth Wang, Dr. Sonia Dhaliwal and Dr. Rachel Pinnow, for their support and involvements at different stages of my research. Specifically, I would like to express my most sincere gratitude and appreciation to my advisor, Dr. Alex Waigandt, for his guidance, patience and continuous support from my master's degree until the completion of my doctoral degree. I would also like to express my appreciation to Dr. Kenneth Wang for contributing valuable perspective and abundant knowledge in international students' research, not only for my dissertation, but also for other projects we have worked on while I was in his research team. I would also like to express my appreciation to Dr. Sonia Dhaliwal taking time to listen to my ideas and

provide valuable input. Moreover, I would like to thank Dr. Rachel Pinnow for providing thoughtful and detailed suggestions during this process, as well as sharing her own experiences related to my research. I am deeply indebted to all of them. 
In addition, I would like to give my deepest appreciation to my family members. Thanks to Dr. Chu-Chun Fu, my spouse, for all the positive encouragement and valuable perspective. Finally, this work is dedicated to my dear parents for investing and believing in me so that I can fulfill my dream. Thank you so much for your understanding and support throughout this journey. 


\section{TABLE OF CONTENT}

ACKNOWLEDGEMENT

LIST OF TABLES vi

LIST OF FIGURES vii

ABSTRACT

CHAPTER I - INTRODUCTION 1

Statement of the Problem 1

Purpose of Study 8

Research Questions \& Hypotheses 8

Basic assumptions 11

Definitions 12

Limitations 13

Delimitations 13

Strengths of the Study 13

Significance of the study 14

CHAPTER II - LITERATURE REVIEW

East Asian International Students 16

International Students' Health and Help-Seeking Behaviors 20

International Students' Cross-Cultural Adjustment and Loss 27

Health Information Seeking Behavior (HISB) 30

Internet Usage and Health Information Seeking Behaviors 36

Health anxiety $\quad 41$

Present study 43

CHAPTER III - METHODS

Participants 44

Procedure 46

$\begin{array}{ll}\text { Instruments } & 47\end{array}$

CHAPTER IV - RESULTS

Preliminary Analysis $\quad 52$

$\begin{array}{ll}\text { Primary Analysis } & 57\end{array}$ 
CHAPTER V - DISCUSSION

Findings from Preliminary Analyses $\quad 67$

Connecting General and Health Anxiety with Well-being 70

Searching Health Information on the Internet and its association with Anxiety 73

Mediating Role of Health Information Seeking Behavior 75

Loss during Cross Cultural Transition $\quad 77$

Limitations and Future Directions 79

Practical Implications $\quad 81$

$\begin{array}{ll}\text { Conclusion } & 83\end{array}$

$\begin{array}{ll}\text { References } & 84\end{array}$

Appendix A - The short-form of Depression, Anxiety Stress Scale 96

$\begin{array}{lr}\text { Appendix B - Health Anxiety Inventory } & 98\end{array}$

Appendix C - Internet Health Information Seeking Behavior 101

Appendix D - The Cross-Cultural Loss Scale $\quad 104$

$\begin{array}{ll}\text { Appendix E - The Satisfaction with Life Scale } & 105\end{array}$

Appendix F - Demographic Questionnaire 106

Appendix G - Research Participation Informed Consent 109

$\begin{array}{ll}\text { VITA } & 112\end{array}$ 


\section{LIST OF TABLES}

Table

Page

1. Demographic Descriptive Characteristics 53

2. Percentage Distribution of Health-Related Variables 56

3. Frequency of Internet Health Information Seeking Behavior 58

4. Bivariate Correlation, Mean, Standard Deviation and Alpha Coefficient

of the Study Variables $\quad 62$

5. Regression Results for Mediation: SHAI-14 $\rightarrow$ iHISB $\rightarrow$ SWLS 64

6. Regression Results for Conditional Indirect Effect:

SHAI-14 $\rightarrow$ iHISB $\rightarrow$ SWLS (Moderator: CCLS)

66 


\section{LIST OF FIGURES}

Figure

Page

1. Hypothesized mediation model examining mediating effect of iHISB on DASS-A and SWLS

2. Hypothesized mediation model examining mediating effect of iHISB on SHAI and SWLS

3. Hypothesized moderated-mediation model 


\begin{abstract}
This study examined the influences of anxiety, health information seeking behavior, cross-cultural loss on satisfaction with life among 186 East Asian international students while studying abroad in the U.S. The results showed that general and health anxiety are both significantly associated with satisfaction with life, while there is a positive association between health anxiety and Internet health information seeking behaviors. Internet health information seeking behavior also mediated the link between health anxiety and satisfaction with life in the U.S. Cross-cultural loss did not moderate the relationship between Internet health information seeking behavior and satisfaction with life as predicted. Results of this study provide additional knowledge about East Asian international students' health, including the connection between general and health anxiety, Internet health information seeking behavior, and satisfaction with life. Findings from this study may have implications for higher education institutions serving international students.
\end{abstract}

Keywords: international student, health information seeking, health anxiety, satisfaction with life, cross-cultural loss 


\section{CHAPTER I \\ INTRODUCTION}

\section{Statement of the Problem}

International students' health is poorly understood, despite their enrollment has topped one million for the first time, reaching an all-time high record of 1,043,839 international students attending U.S. universities in 2015-2016 academic year (Institute of International Education, 2016). Beyond the extensive and growing financial contribution international students and their dependents bring to U.S. economy, international students have been said to "...enrich the campus community and expand our intellectual, ethnic, and cultural experiences” (Carr, Koymama, \& Thiagarajan, 2003, p. 131). Thus, given their influences on U.S. universities and colleges, more efforts should be dedicated to gaining better understanding of international students' health while studying abroad. In response to the changing and increasing demographics of international students on campus, incorporating culturally specific and sensitive approaches when it comes to health care planning, education and promotion will be a step to the right direction for higher education institutions.

Improving students' health on colleges and universities has been the focus of The American College Health Association since its inception in 1920. While "assessing and understanding the health needs and capacities of college students is paramount to creating healthy campus communities" (American College Health Association, 2008, p. 469), others (e.g. Prescott, 2011) have also argued that the attention to student health goes beyond individual benefits, as it may actually improve overall institutional objectives such as student retention. Focusing on understanding and improving health will not only 
increase the possibilities of current international students' academic success and matriculation, but also can reflect positively on U.S. institutions in terms of their attention and care towards improving international students' experience while studying abroad. This may potentially make the prospects of studying abroad to the U.S. more appealing, attractive and practically feasible in the long-term in terms of recruiting potential incoming international students.

Another reason to examine international students' health is to provide culturally sensitive treatment to international students, considering there are significant cultural differences related to health care beliefs and therapies that may prevent international students from seeking appropriate health care (Rew, 1997). Within studies focusing on their psychological health and well-being, many international students reported reluctance in seeking help due to language barriers, cultural differences and stigma regarding help-seeking (Li, Wong, \& Toth, 2013). Additional deterrence to international students' health may include the inability to take complete responsibility for their own health care (Sadler, 2005), often compounded by the delay in treatment which may result in more immediate and serious need for healthcare when they finally do require treatment (Grace, 1997). These reasons may contribute to difficulties and further complications for student health care centers on located university campuses when providing medical care for international students.

International students may have different help seeking pattern and behavior when it comes to their health management. Not surprisingly, it has been said that most international students only seek medical attention from physicians or health professionals as a last resort (Collins, 2001). As compared with the general U.S. student population, 
fewer international students seek medical attention for common illnesses. Instead, most of them are more likely to seek help from peers or engage in preferred personal care treatments, such as natural herbal remedies or medications brought from home country. To further illustrate this using a study examining international students from two Asian countries, China and India (Rothstein \& Rajapaksa, 2003), while these international students shared similar health beliefs rooted in Western medicine as domestic students born in the U.S., they have also placed importance on alternative sources of caring for their health, such as botanic drugs, non-prescriptive medications, non-Western medical providers, vitamins. Findings of these studies illustrate the complexity of recognizing possible acceptance of common Western approaches to medicine among international students, while at the same time, it is important for student health services on campus not to disregard or disrespect alternative approaches to care international students might exercise in terms of their health management.

Within existing literature examining international students' experiences abroad, for those focusing on health-related topics, only a few have been the ones conducted in the U.S. while others were conducted in countries such as Australia. The few that focused on international students in the U.S. explored topics such as international adolescent students' health (Collins, 2001) or perception regarding substance use and available services at university (Perko, Woodhouse, Jones, \& Green, 1996), while others primarily examined international students' psychological health-related behaviors, such as anxiety, depression and stress (Mitchell, Greenwood, \& Guglielmi, 2007), substance abuse (Miyazaki, Bodenhorn, Zalaquett, \& Ng, 2008) and eating disorders (StarkWroblewski, Yanico, \& Lupe, 2005). While there might be similarities and 
commonalities in the studying abroad experiences in general, regardless of the geographic location of where the education occurs, however, there might be significant differences in students' demographic characteristics, motivations to pursue a degree abroad, as well as specific cultural experiences related to the specific country or educational setting they are in. Particularly, with the U.S. currently hosting over 1 million international students pursuing their studies, it is imperative that more studies are conducted in the U.S. to ensure that the findings will applicable to the international students here.

One's health can significantly impact other areas of life, such as their academics and well-being in general. In a study that surveyed international students who were studying abroad in Australia, majority reported to have "excellent" or "good" physical health. However, for students who perceived themselves to have "poor" health, or that their health was worse in Australia than at home, they felt that their health status strongly interfered with their academics. Furthermore, another issue these international students in Australia appeared to face is the heightened sense of anxiety, even more so than depression or stress, and Asian students more so than their non-Asian counterparts (Rosenthal, Russell, \& Thomson, 2008).

Not only is there a dearth of researching examining international students' health, when they are studied, one criticism of current studies is that international students are often treated as a homogenous group regardless of their countries of origin and cultural differences. East Asian international students, for instance, representing more than half of the total international student population, are said to experience more acculturative stress due to having greater cultural distance with American culture (e.g. Kaul, 2001) and 
have reported experiencing more stressors (Myers-Walls, Frias, Kwon, Ko, \& Lu, 2011), as compared to their European counterparts. Thus, given the above considerations, it is imperative for more culturally sensitive research to be conducted on East Asian international students and their health.

For many people, especially those who may be on a budget or seek convenient solutions such as graduate students, will most likely not go to a doctor first if they can simply go "online" to search for the information they need. Particularly with how accessible and convenient the Internet has become, taking into account unique challenges international students face and cultural considerations, it has been said that they primarily use the Internet for the purpose of information seeking, in addition to relaxation, entertainment and social connections (Ye, 2005). With advances in modern technology, it has revolutionized how we live day to day, including how we seek information and make decisions.

Online health information has become as an important health information resource (Cheong, 2007). Even for American adults in the general public, while majority of Americans (70\%) received information, care or support related to their health from medical professionals, more than 100 million Americans seek general health information online (Pew Research Center, 2012). Within the past 12 months, seventytwo percent of American Internet users have gone "online" and sought the Internet for some type of health information ranging from general health issues, health insurance, to specific disease or medical problems (Fox, 2008). As East Asian countries are said to have highest percentages of Internet users in Asia with more than eighty percent of their citizens having access to the Internet (Miniwatts Marketing Group, 2015), it is likely 
international students from those countries access Internet to seek information about their health. Health information seeking behavior (HISB), or Internet health information in particular, may be the key to improving health and increasing quality of life.

As they move from their country of origin and transition to study abroad in the U.S., international students may experience a sense of loss related to caring for their health. In addition to cultural shock, the concept of loss has been linked with crossing national boundaries (Arredondo-Dowd, 1981). Cross-Cultural Losses Scale (CCLS, Wang, Wei, Zhao, Chuang, \& Li, 2015), a recent developed instrument aimed at measuring losses sojourners experience living outside of their countries. Conceptually, aspects on the CCLS may be particular related to health, such as individual's competence living in a new country or changes in national privileges with items such as having "less access to welfare (e.g., health care, benefits) for citizens" (Wang et al., 2015, p 6). In addition, the overall sense of cross-cultural losses may impact one's psychological state (Casado \& Leung, 2002), as they were positively associated with negative affect, negatively associated with life satisfaction and subjective well-being. Thus, there is definite value in further exploring perceived cross-cultural loss and the connection between health information seeking behavior and international students' adjustment in the U.S.

In a systematic review of international students' literature, Zhang and Goodson (2011) found that stress, social support, acculturation and self-efficacy to be among most frequently used predictors of psychosocial adjustment. As anxiety has been said to be a reaction to stress, it is conceptually conceivable that heightened anxiety after crosscultural transition from their home country to the U.S. may impact one's health 
information seeking behavior and consequently satisfaction with life. There is also theoretical basis to support this assumed connection between anxiety and information seeking. For example, Afifi and Weiner (2004) proposed the Theory of Motivated Information Management (TMIM; Afifi \& Weiner, 2004) and posited that anxiety is likely to follow the experiences of uncertainties and discrepancies, and that one possible way of coping with this is what triggers individuals to seek more information in order to decrease their anxiety. Previous studies have also provided additional evidence for this. For instance, Eastin and Guinseler (2006) found that moderately anxious individuals were more likely to seek higher amounts of online health information and make medical decisions such as obtaining appointments for medical professions, while their loweranxiety counterparts were less likely to visit a doctor after their search for information online.

As International students may experience heighten anxiety regarding their health due to unfamiliarity to their new environment and possibly need to deal with physical and psychological health issues that they did not have to previously, it is likely that they will seek more information particularly online, since they do not have their previous support nearby. Depending on the level of cross-cultural losses they experience, it is possible that for international students, having anxiety regarding their health will lead them to seek more information online, and their satisfaction with life might consequently change as a result. Particularly considering international students' cross-cultural transition from their country of origin to the U.S. and the unique barriers they commonly experience when seeking help, examining how their health information seeking behaviors may be related to their adjustment and well-being in the U.S. and provide a comprehensive picture of 
their overall health and adjustment in the U.S.

Given their increased presence on U.S. university campuses combined with the relative lack of focus on their experiences in the U.S. within current research, there is a need to further study East Asian international students' health, particularly how their health information seeking behavior relates to their adjustment while studying in the U.S.

\section{Purpose of Study}

The purpose of this study is to address the overall lack of health-related studies in the international students' literature. Specifically, this study aimed to explore associations among health Information seeking behavior, anxiety, cross-cultural loss and satisfaction with life among East Asian international students.

\section{Research Questions \& Hypotheses}

The research questions and hypotheses were listed as followed:

Research question 1: What is the relationship between anxiety and satisfaction with life?

Hypothesis 1: Overall, it is hypothesized that the higher an individual's anxiety, the lower their well-being will be. Specifically, it is hypothesized that there will be a significant, negative relationship between general anxiety and satisfaction with life. Also, the other hypothesis is that there will be a significant, negative relationship between health anxiety and satisfaction with life.

Rationale: Asian international students appeared to struggle more with anxiety compared to their non-Asian counterparts (Rosenthal, Russell, \& Thomson, 2008), even more so than with depression and stress when living in Australia during their sojourn, while international students from Asia who were studying abroad in Norway are also 
more likely to report being less satisfied with life in comparison to their European and North American counterparts (Sam, 2001). As current literature has not explored much of the relationship between aspects of psychological distress (e.g. anxiety) and psychological well-being (e.g. satisfaction with life), particularly among Asian international students studying in the U.S., it is worth further investigating the link between the two, specifically in the context of health. Both general and health-specific anxiety will be examined to see if the two differ in their relationship with satisfaction of life, as these constructs have not been previously investigated and compared among international students population.

Research question 2: What is the relationship between anxiety and health information seeking behavior?

Hypothesis 2: It is hypothesized that there will be a significant, positive relationship between anxiety and health information seeking behavior. The more anxious someone is, the more likely they are to engage in health information seeking behavior.

Rationale: Given Afifi and Weiner's (2004) propositions in the Theory of Motivated Information Management (TMIM), theoretically connecting anxiety with information seeking, it is plausible that particular for international students who have moved from their country of origin to the U.S., facing unfamiliarity with their new environment, particularly the healthcare system and approaches, for many of them, they will seek out more information when dealing with general or health-related anxiety. Further exploring this connection among international students will provide further insights to Eastin and Guinseler's study (2006) where they provided evidence for the moderating role of anxiety in health information seeking and taking action as a result of 
the information obtained.

Research Question 3: Does health information seeking behavior mediate the relationship between anxiety and satisfaction with life?

Hypothesis 3: It is hypothesized that health information seeking behavior will mediate the relationship between anxiety and satisfaction with life. Specifically, it is hypothesized that as for those whose anxiety increases, Internet health information seeking behavior will increase as well, and consequently satisfaction with life will decrease.

Rationale: Following the premise of hypothesis 1, as international students experience anxiety related to their health while studying abroad, their satisfaction with life is likely to suffer and decline as a result. Adding the mediating role of Internet health information seeking into the relationship between anxiety and satisfaction with life makes sense when considering Theory of Motivation for Information Management (TMIM); as anxiety arise, international students are likely to seek out more information online, potentially to cope and manage that increase in anxiety, and as a result, their satisfaction with life might decline as a result of having additional information.

Research Question 4: How might the level of loss associate with cross-national borders change the relationship between health information seeking behavior and satisfaction with life?

Hypothesis 4: It is hypothesized that cross-cultural loss will moderate the relationship between health information seeking behavior and satisfaction with life. For those who experience greater sense of loss, the more health information they seek and obtain, the lower their satisfaction with life will be. 
Rationale: Losses related to cross national and cultural border have been said to have serious impact on individuals, such as international students (Wang et al., 2015), while living outside of their country. For instance, their competence in navigating new environment may be limited or lost, with either limited or no longer having access to national privileges, welfare and benefits restricted for citizens, which may consequently impact their psychological well-being, as heighted sense of loss has been linked with a decrease in life satisfaction and subjective well-being (Casado \& Leung, 2002). Thus, exploring the moderating role of cross-cultural loss in the relationship of health information seeking online and satisfaction with life makes conceptual sense, as the more heightened an individual's sense of loss is, the more they will be impacted by the information they received and the more decline they are likely to experience in terms of satisfaction with life.

\section{Basic assumptions}

The basic assumptions of the study were highlighted below:

1. It is assumed that the sample of East Asian International students that will be surveyed will be representative of all East Asian International students.

2. It is assumed that while there might be differences in culture amongst East Asian international students, they are homogenous enough to be studied together.

3. It is assumed that all respondents will answer all survey questions honestly and to the best of their abilities.

4. While the HISB inventory that will be used in this study has only been used and validated with immigrants, it is assumed that it will be appropriate to assess international students' health information seeking behaviors. 


\section{Definitions}

1. In this study, international students are defined as students with a temporary visa studying in a country outside of their country of citizenship in pursuit of higher education (Souto-Otero, Huisman, Beerkens, de Wit, \& Vujić, 2013).

2. "Health information seeking" will be defined as "process of finding the information needed for personal decision making related to health and medical issues" (Wei, 2014)

3. In this study, the term "Health information seeking behavior" (HISB) will be defined as "the active efforts to obtain specific information above and beyond the normal patterns of media exposure and use of interpersonal sources" (Niederdeppe et al., 2007, p. 154).

4. "Cross-Cultural Loss" will be defined as a "loss of roots, which includes the geography, support, people, cognitive world, and status that individuals had back in their home country", applicable for most sojourner and immigrant groups. (Wang et al., 2015, p 42)

5. "Anxiety" is defined as an emotion characterized by feelings of tension, worried thoughts and physical changes like increased blood pressure (APA, n.d.).

6. "Health anxiety" refers to "concern about health in the absence of a pathology or excessive concern when there is some degree of pathology" (Lucock \& Morley, 1996, p 137).

7. "Satisfaction with Life" is defined as ones overall evaluation of life as a whole, rather than their current feelings and emotions (Positive Psychology Program, 2015). 


\section{Limitations}

1. As this study primarily examines East Asian International students, the results may not be generalized to International students from other Asian countries or other parts of the world.

2. The results may not be generalized to East Asian International students studying in other countries (e.g. UK, Canada, Australia, ... etc).

3. As there might be a cohort-effect, the results of this study may not apply to international students who are not currently studying in the U.S.

4. After having crossed cultural boundaries, EAIS's health seeking behavior in the U.S. may not be reflective of how their behaviors are like in their own country.

\section{Delimitations}

1. A delimitation is that this study will only examine at East Asian international students currently studying in the U.S. on F-1 or J-1 visa to ensure that participants are as homogenous as possible.

2. Another delimitation is that this study will only use self-report online questionnaire, as this is the most efficient and effective way to obtain data with maximum responses.

3. Another delimitation is that this study only focuses on their Internet health searching behaviors instead of different types of Health Information Seeking Behavior, as Internet appeared to be the primary ways of searching information for this generation of international students.

\section{Strengths of the Study}

With a focus on health information seeking, one of the primary strengths of this 
study is that it will contribute understanding aspects of adjustment and cross-cultural transition of international students studying in the U.S., a population on U.S. higher institutions that has been growing at an incredibly rapid speed.

After examining the literature, while the subject of international students' health has been addressed to a certain extent, one limitation of the current literature is that many of these studies focused on international students in other parts of the world outside of U.S. such as Australia or Europe. Due to differences in geographic location, culture, differences in higher education as well as potential differences in the composition of international students who chose to pursue their studies in Australia or Europe, while there is definite merit and value of referencing findings of these studies when conceptualizing adjustment that international students in the U.S., it would not be ideal or even culturally sensitive to assume these different groups of international students have the same experiences. Thus, another contribution of the current study is to add to the literature focusing on health among East Asian international students in the U.S., specifically in regards to their Internet health searching behavior and its link to psychological distress and well-being within the U.S cultural context.

\section{Significance of the study}

There are currently no studies to date that focuses specifically on East Asian International students' Internet health information seeking behavior (iHISB) and outcome on their adjustment and satisfaction with life. With the Internet becoming such prevalent part of everyday life, searching for information online, specifically health-related information, will most likely become more common in the future, especially for those who may not be familiar or connected to the healthcare system around them, such as 
international students and others living in a new country. With East Asian international students comprising of the current largest portion of the foreign students in the U.S., examining international students' iHISB may be crucial in understanding to their adjustment and well-being in the U.S. It is also essential to understand East Asian international students' iHISB in order to provide accurate and reliable health-related information for healthcare providers while providing services. Therefore, this study tried to seek to better understanding of East Asian international students' iHISB, cross-cultural loss, anxiety and satisfaction with life. 


\section{CHAPTER II}

\section{LITERATURE REVIEW}

Despite complexity of international students' adjustment after they come to study in the U.S., very little is known about their health and how it affects their overall well-being. Little is known about how aspects of their psychological state of being (e.g. general anxiety or health anxiety, or satisfaction of life), combined with unique crosscultural factors related to being an international student (e.g. cross-cultural loss) might be related with health behaviors (e.g. Health Information Seeking Behaviors). Thus, the present study will examine the relationship between anxiety (general and healthspecific), Internet health searching information behaviors, cross-cultural loss, and satisfaction with life. Particularly, the mediating role of Internet health searching information and moderating role of cross-cultural loss will be examined in relation to anxiety and satisfaction with life.

This chapter includes a review of current research on (1) East Asian International Students, (2) International Students' Health and Help-Seeking Behaviors, (3) International Students' Cross-Cultural Adjustment and Loss, (4) Health information seeking behavior (HISB), (5) Internet Usage and Health Information Seeking Behaviors, and (6) Health Anxiety.

\section{East Asian International Students}

With international students becoming an integral and expanding part of the U.S. higher institution landscape, it is important to consider and incorporate unique characteristics within this population as campuses focus on objectives of improving college and universities students' health. International students' enrollment continuously 
reaches record high year after year. Having increased over 59.5\% since the past decade, the enrollment of the overall international student population in the U.S has reached a total of 1,043,839 students in U.S. universities in the 2015/16 academic year, an all-time high, which consequently brought over 35.8 billion dollars of financial contribution to the U.S. economy (Institute of International Education, 2016). It is worth noting that there are multitudes of benefits associated with promoting international education on U.S. campuses beyond the considerable financial incentives for the overall economy international students and their dependents bring each year, including intellectual, ethnic, and cultural benefits for higher education institution (Carr et al., 2003), surrounding community and even society overall. Despite the increase in their presence on U.S. higher institutions, there is relatively little known about international students' health.

Considering the context of entering college and universities, it can be an exciting and unnerving process for any students. While many stressors international and domestic students who enter universities for undergraduate and postgraduate programs will experience may be similar (e.g. navigating and becoming acquainted with a new environment and reestablishing social support), however, for international students, challenge associated with moving away from familiar environment such as home, family and community can be magnified by language, cultural and scholastic differences (Rosenthal, Russell, \& Thomson, 2008). While many of the international students appeared to be able to complete their studies with relatively few problems (Chen et al., 2002) or be "well-adjusted" (Wang et al, 2012, p 429), there are cultural and individual differences attributing to how well they adjust to the U.S., as others may be "culturally shocked" (Wang et al, 2012, p 430), or "consistently distressed" (Wang et al, 2012, p 430) 
when looking at their adjustment profile over time.

As International students' well-being have been said to be affected by their distinctive cultural background (Deurmert et al., 2005; Rosenthal, Russell \& Thomason, 2006), thus, it is important to begin to recognize the diversity and inter-group differences, as these factors might impact their adjustment in the U.S. A criticism and one of the current challenges related to conducting studies on international students' health or in general is that researchers tend to lump them together as if they are one culturally homogenous group, regardless of differences in countries of origin and culture. Intentionally studying subgroups of international students when conducting research may be one step closer to achieving more meaningful and culturally appropriate understanding of their experiences.

More attention is needed to examine acculturation and adjustment process of East Asian international students. Representing more than half of the total international student population, with more than $60 \%$ of international students coming from East Asian countries such as China, India, South Korea and Taiwan, within this sub-group of international students, $40.9 \%$ of them pursuing undergraduate and $36.8 \%$ pushing for graduate degree respectively (Institute of International Education, 2016). In addition to their representation among overall international student population, East Asian international students are said to experience more acculturative stress due to having greater cultural distance with American culture (e.g. Kaul, 2001; Ye, 2005) and have reported experiencing more stressors such as adjusting to new cultures, feelings of isolation, and language difficulty (Myers-Walls et al., 2011), as compared to their European counterparts. While there are cultural and individual differences that exist 
among East Asian international students having come from different countries or regions in Asia, there are sufficient similarities and commonalities connecting them all as well. These commonalities include collectivistic worldview orientation (Frey \& Roysircar, 2006), which tends to place value on harmony and group affiliation.

Other values that appeared to be distinctive and shared among many Asian ethnic groups include conformity to norms, restraints in emotions, humility, suffering for the sake of others and the greater good (Lee, Ditchman, Fong, Piper, \& Feigon, 2014). The importance of family is also often highlighted in cultural-specific concepts such as filial piety (Miville \& Constantine, 2007), significance of achievement in earning family recognition and respect, fear of losing face for both self and family (Zane \& Mak, 2003), and distinct hierarchical family structure (Kim, Atkinson \& Yang, 1999). Adherence to many of these cultural values appear to deter help seeking behaviors among Asian and Asian Americans, particularly when it comes to mental health services.

For many East Asian international students, their overall satisfaction with life had an inverse relationship with aspects of acculturative stress, fear, perceived hatred, perceived discrimination and cultural shock. In other words, the higher an international student's acculturative stress become, the more likely their life satisfaction and wellbeing will suffer (Ye, 2005). Another challenge East Asian international students are said to experience is difficulties in establishing meaningful and satisfying friendship with U.S. born students, which may lead them to experience a certain level of disappointment, loneliness, isolation or alienation as a result (Chen, 2006). Combining the challenges and difficulties East Asian international students encounter within the U.S. context, more attention is needed to better examine aspects of their adjustment process in the U.S. 


\section{International Students' Health and Help-Seeking Behaviors}

Previous research on international students has shed light on their experiences and adjustment in the U.S. In health-related studies previously conducted on international students within the past two decades, researchers have focused on examining international students' psychological health-related behaviors, such as anxiety, depression and stress (Mitchell, Greenwood, \& Guglielmi, 2007), substance abuse (Miyazaki, Bodenhorn, Zalaquett, \& Ng, 2008) and eating disorders (Stark-Wroblewski, Yanico, \& Lupe, 2005). However, there are still no empirical studies up to date that focus on international students' health-seeking behaviors and explore alternative ways they might seek out health information.

Related to personal health management, international students and domestic students vary in their level of anxiousness related to health and their efficacy in addressing their concerns with medical professionals. International students have reported to have higher anxiety related to health or medical concerns, compared to their domestic counterpart born in the U.S., while domestic students indicated having higher efficacy talking to medical professionals about a current medical concern (Austin, 2013). Overall, the challenges and threats to well-being have been well documented in the transition process associated with becoming an international student (Rosenthal, Russell, \& Thomson, 2008).

For many international students, being away for home, some for the first time in their lives, one of their primary challenges is to deal with health related issues in an unfamiliar environment, navigating healthcare system and insurance policies different than that of their own countries. For instance, Lydia, an international student from China, 
described the following, contrasting differences in health care system and approaches in her home country and the U.S.

In China we pay insurance and we go to the hospital if we need a surgery. The company will pay for us, covers the pay. But here the insurance only covers the clinic fee. It's like, if you have a knee surgery you still have to pay for it, and it's very expensive. (Carmack, Bedi, \& Heiss, 2015, P 58)

Similar to voices of many other international students from her own country and other corners of the world, Lydia is not alone in struggling to cognitively comprehend the differences between two different healthcare systems as well as the financial implications of seeking medical help in the U.S. Anecdotally, many international students are too often shocked at the price of healthcare in the U.S. after they have had to seek medical treatment beyond the common illnesses, such as seeking urgent and emergent care or major surgery.

In addition to difficulties figuring out the healthcare system in their new country, many international students such as Maura talked about unclear communication about health insurance. Below is a quote from Maura explaining how a simple message about the importance of keeping one's health insurance card is commonly unclear, despite many university international student offices set up orientation to explain important information about their new lives in the U.S.:

Most of my international student friends, they just don't know what's the insurance for. And even they just get the insurance card and the little discount two cards. There are like two things. They just don't know why they're receiving it and what's this for, even though they participated in the orientation and 
everything. And one of my friends, he just threw it away. Because he doesn't know what it is, just send it to our mailbox. So he thought he was just throwing out junk, so funny (Carmack et al., 2015, P 58).

Combining the unfamiliarity with new healthcare system, unclear communication about important information pertaining to health insurance, along with the fear of high cost of medical treatment, common sentiments shared by many international students include confusion, frustration and even anger, especially during initial stages after they arrive in the U.S. These sentiments are often exacerbated and further intensified when international students take into consideration the relative high cost of mandatory health insurance and the imbalance between cost and coverage of services they receive despite having health insurance (Carmack et al., 2015). Within a qualitative study using grounded theory to examine international students' experience with university student health centers, one clear theme is the feeling of lack of control and choices associated with health-related affairs (Cheng, 2005), which echoed sentiments articulated by many international students' experiences. For many students, because of the drastic differences between healthcare system and approaches in their home country and the U.S., even if they were made aware and cognitively understood information related to U.S. health insurance prior to coming to the U.S., it is usually not until they come to the U.S. and see what health insurance entail do they gradually start getting a sense of what insurance can or cannot do for them. For instance, Kate explained:

Before I came here I know that I'm going to have insurance and student insurance. And then, it's like \$500-something for international students, so I thought it's going to cover something, but it was different. I went to T Health one time and 
they checked my body once and then got medicine, and then they don't cover anything. Maybe like 50 percent is covered, the medicine, but it didn't cover anything. And all the international students that I met who've been to T Health, they said, "What's the health insurance for? We're just paying $\$ 500$ every semester, and what's that covering for?" There's a lot of confusion. (Carmack et al., 2015, P 60)

Another aspects of international students' experiences related to health and medicine in the U.S. is what Carmack and colleagues (2015) referred to as "triaging your own health" ( $\mathrm{p}$ 60). Triaging refers to the decision-making process international students often need to undergo in order to make a determination of what is the best approach in managing their health, particularly at times of illnesses, whether it is to seek help via university student health center, local hospital or clinic, or find a way to "self-treat". While this may not sound challenging for an individual who might have been born here or has sufficient knowledge about U.S. healthcare and basic information about health, many international students have grown up in countries where they simply sought treatment at hospital if they are sick, regardless of severity. Thus, health and particularly illness related decisions may be tricky for them to make the right determination of what to do should they become ill or have symptoms they are concerns about. Maura shared about information she received at a student orientation when she first came to the U.S.: We had orientation in the ISS [International Student Services] for international students. And they said, "We have T Health, it's a hospital at [our university]." And they said, "Don't go there if you have headache or if you get a cold. Just don't go there. If you have a serious thing, just go there." Otherwise, just don't go 
there. That's what I remember. (Carmack et al., 2015, P 60)

If there is anything to be learned about potential ideas to improve communication and explanations to international students regarding U.S. healthcare system. It would appear that providing information and guidelines about how U.S. categorizes illnesses and the appropriate, corresponding facilities to go to may immensely help international students in better making informed and accurate determination about how to seek help medically whenever the need arises. However, as these types of information are often either not communicated at all, or remains unclear to students even when explained to them, as evidenced by the quote above. Instead of providing education and information about where to seek help depending the level of severity and urgency of a medical condition (e.g. when to go to the university student health centers versus the local hospital), but the underlying messages from the quote above is potentially almost fearinducing by inadvertently reinforcing the message of “don't seek help, unless it is really, really serious". As a result, one way many international students have used to cope with medical and health issues is to avoid seeking professional medical treatment as much as possible and instead find alternative ways to care for their health, such as turning to local pharmacy or grocery superstore for advice as it is much more convenient and predictable in terms of cost if there is any associated with purchasing medication. Many students even bring medication from home with them in order to avoid even going to local pharmacy. All of these behaviors are often positively reinforced when international students also see their friends doing the same thing.

On a related note, too often, logistical and technical barriers of not knowing how to seek help prevent them from doing so. For instance, in regard to health services on 
campus, within a sample of nearly 1000 international students studying in Australia (Russell, Thomson, \& Rosenthal, 2008), out of the $41.2 \%$ who perceived they needed help, only $62 \%$ took action and sought treatment. When they did seek services, Asian students reported significant less satisfaction with availability of appointments compared to their non-Asian counterparts. Top reasons for not seeking help varied from thinking that their problems were not important enough, unaware of location, fees, methods of obtaining appointments for services, as well as being afraid and discomfort regarding seeking help.

Significant cultural differences related to health care beliefs and therapies may prevent international students from seeking appropriate health care (Rew, 1997). Many international students reported reluctance in seeking help for health reasons due to language barriers, cultural differences and stigma regarding help-seeking (Li, Wong, \& Toth, 2013). After taking into consideration international students' cross-cultural transition from their country of origin to the U.S. and the unique barriers they commonly experience when seeking help, barriers to seeking professional help do not seem to be only limited to psychological health-seeking. Rothstein and Rajapaksa (2003) indicated that for students born in countries such as China and India, even when they share similar preventative and therapeutic health beliefs of Western medicine with their U.S.-born counterparts, many of their health beliefs are still rooted in traditional cultural practices. Findings from Collins's study (2001) examining adolescent international students between $9^{\text {th }}$ and $12^{\text {th }}$ grade indicated that most international students only seek medical attention from physicians or health professionals as a last resort. For instance, as compared with the general U.S. student population, fewer international students seek 
medical attention for common illnesses. Instead, most of them are more likely to seek help from peers or engage in preferred personal care treatments, such as natural herbal remedies or medications brought from home country (Collins, 2001).

As health issues do not exist in a vacuum, it may impact other areas of an individual's life beyond illnesses. In a study conducted by Rosenthal and colleagues (Rosenthal, Russell, \& Thomson, 2008) with international students at an Australian University, over two-thirds (64.7\%) of international students in their sample rated their physical health as "good" or "excellent", while only $2.6 \%$ of international students indicated that their health was "poor". While only $5.3 \%$ of international students reported having experienced significant interference on their studies as a result of healthrelated problems, not surprisingly, for those international students who did perceive themselves as having "poor" physical health or that their health was comparatively worse in Australia than at their home countries. As a result, they felt that their health status strongly interfered with their academics' performance.

With the goal of helping international students achieve academic success in mind, understanding perception related to health among international students could be helpful when planning for health care services as well as educational programs on campus. Within the available existing studies looking at international students in the U.S., one study conducted at a U.S. Midwestern university examined perceived needs for student health services on campus for Chinese and Taiwanese international students. When asked about their top main health-care concerns, the top of the list included "a lack of education on how to care for self, overuse of the emergency department, and lack of education about how their body works including reproductive health" (Ellis-Bosold \& 
Thornton-Orr, 2013, p 156). Specifically, one question asked the students who they think is responsible for their health, nearly a third of the students sampled indicated the university with similar percentages reported themselves, and another $14 \%$ stated the internet student services at their universities. Given that majority of them did not consider themselves to carry the majority or sole responsibilities for healthcare, many of them might feel a sense of disappointment, disconnection and reluctance to seek help if they do not feel that their health is being cared for by the university or the International Center on campus.

\section{International Students' Cross-Cultural Adjustment and Loss}

International students have been said to experience a variety of difficulties associated with their cross-cultural transition from their home country to the U.S. and during their stay in the U.S. Scholars have identified several challenges for international students, such as confusion of identity and values, an effortless sense of belongingness, homesickness, losses of self-efficacy, as well as their ability to effectively navigate in a new cultural context, which often lead to stress, anxiety, and other psychological problems (e.g. Rakhsha, 2002; Johnson \& Sandhu, 2007; Nilsson \& Anderson, 2004). In addition, Yeh and Inose (2003) indicated that international students could experience many challenges due to discrimination, language and cultural barriers, difficulties with academics and finances, interpersonal problems, and loss of social support (Yeh \& Inose, 2003).

Being physically present and interacting in the new environment using a language different from their own can be extremely challenging, let alone tackling physical and mental health issues by navigating a health care system that may be very different than 
the one they have been previously familiar with. Rosenthal and colleagues (Rosenthal et al., 2006) posited that international students' level of connectedness was found to be a strong predictor of their "satisfaction with aspects of daily life and health, such as living arrangements, financial support, lifestyle balance, and with their levels of self-esteem and depression" (p. 5). In another study, when asked about feelings of dislocation, strangeness and discomfort living in Australia, international students reported that their highest levels of stress came from "missing a familiar way of life and loved ones" (Thomson, Rosenthal \& Russell, 2006, p 6), reflecting significant cultural loss associated with crossing national borders. It is important to note that Asian students in particular reported feeling that they do not belong significantly more often than their non-Asian counterparts, which may tie in with the greater issue of not having social support locally, potentially contributing to and exacerbating a sense of loss. In other words, no longer living in a familiar environment with resources they were used to, the loss of social support and potential disconnectedness in their new environment may exacerbate adjustment difficulties and magnify cultural differences many Asian international students may already be experiencing.

Other than no longer having access to previous social support and connection, international students may experience certain degrees of loss or anxiety when it comes to their health, particular with navigating the healthcare system in the U.S. The concept of loss has long been linked with crossing national boundaries (Arredondo-Dowd, 1981). For instance, Rakhsha (2002) have separated loss for international students to include tangible ones and intangible ones. Tangible losses include access to concrete aspects of their home country, such as food, people, places and network, while intangible ones may 
be further categorized into three types: effortless sense of belonging, relevancy of knowledge, and self-efficacy, which Wang and colleagues (Wang et al., 2015) later combined into two main categories, social and competency, in the development of a cross-cultural losses scale.

Relating concepts of cross-cultural loss to international students' health in particular, tangible losses may include access to familiar healthcare facilities, medical providers, medications, and perhaps even alternative treatments they might have used, but are no longer able to access now that they are living in abroad, while the intangible losses may include relative limited relevant knowledge of where and how to seek medical treatment and difficulties navigating healthcare system, or decreased in self-efficacy in "triaging" or making medical decisions as discussed previously. Currently, it is mandatory for international students to maintain qualifying health insurance of minimum essential coverage during their whole stay in the U.S. Confused about the complexity of the U.S. healthcare system and various healthcare plans available or provided to them, it is possible that many international students may sense of loss or anxiety while accessing to U.S. healthcare system (Wang et al., 2015), no longer having the same level of familiarity as they did with systems and resources in their home country. Moreover, in the development of the Cross-Cultural Losses Scale (CCLS), in addition to aspects of loss already been captured in previous research studies, Wang and colleagues (2015) further proposed another aspect of loss, which can be characterized as no longer having "rights and privileges that come with having citizenship of the residing country", applicable to many sojourners such as international students.

Conceptually, specific items on the CCLS may be related to health for 
international students. For instance, examples include assessing individual's competence living in a new country with items such as "have less knowledge of the resources available in your environment", as well as changes in national privileges with items such as "experience more restrictions as a foreigner" or "have less access to welfare (e.g., health care, benefits) for citizens" (Wang, Wei, Zhao, Chuang, \& Li, 2015, p 6). In addition, the overall sense of cross-cultural losses may impact one's psychological state (Casado \& Leung, 2002), as they were positively associated with negative affect, negatively associated with life satisfaction and subjective well-being.

\section{Health Information Seeking Behavior (HISB)}

Health related issues impact every one of us on a daily basis, whether we are conscious of them or not. Gathering health information in order to make personal decisions related to health and medical reasons is fairly common, and has been demonstrated to play a critical role in health education and promotion, as it has the potential to affect behavioral change, usage of health services and overall making more informed decisions (Wei, 2014). Health information seeking behavior (HISB), referring to "the active efforts to obtain specific information above and beyond the normal patterns of media exposure and use of interpersonal sources" (Niederdeppe et al., 2007, p. 154), can be very complex, as it not only includes the ability to access and comprehend the information gathered, it also encompasses the motivation to search for information often determined by one's health literacy as well as cognitive and social skills (Wei, 2014). Seen as a "highly personal activity, driven by situational and contextual factors" (Wei, 2014, p 424), researchers such as Niederdeppe and colleagues (2007) have identified components of HISB to include: 
any non-routine media use or interpersonal conversation about a specific health topic as well as behaviors such as checking a special program about a healthrelated treatment, using search engines to find information about a particular health topic on the Internet, and/or posing specific health-related questions to a friend, family member, or medical practitioner outside the normal flow of conversation (p. 154).

In addition to the definitions above, there have been varying discussions on how to operationalize the concept of HISB. For instance, Lambert and Loiselle (2007) shared that many researchers tend to include components of health information such as, 1) types of information sought, 2) amount of information sought, 3) description of sources used, or 4) consequent actions implemented as the result of information sought, while others examined HISB by simply looking at specific kinds of health information such as illness related information about diseases and disease process, wellness and self-care related information as well as self-management strategies. To examine this topic more broadly, HISB could broadly be divided into two dimensions, either the information dimension, including types and amount of information sought in terms of content and diversity), and method dimension focusing on "discretionary actions individuals use to obtain health related information and sources of information used" (Lambert \& Loiselle, 2007, p 1013). While these components and categories are important to note and keep in mind when discussing HISB, what is even more crucial is that capturing a person's HISB can be incredibly dynamic and complex, as it may vary according to changing individual and contextual factors and time. 
Health information seeking behavior (HISB) has gained significant attention within research field, as the number of studies examining this specific construct has doubled within the past decade (Anker, Reinheirt \& Feeley, 2011). Lambert and Loiselle (2007) indicated that HISB is an important construct within the health profession discipline and has been conceptualized as "a key coping strategy in health-promotive activities and psychosocial adjustment to illness" (p.1006). Therefore, understanding HISB on general public would not only help health professionals provide useful resources and information more accurately, but also improve individuals' quality of life indirectly through offering proper health education and disease prevention information to the target populations.

Examining antecedents and motivations for individuals for seek HISB, while it seemed intuitive that a person might seek information if he or she needs it, however, the need alone might not prompt an individual to seek health related information. Personal and situational factors have been identified to impact what type and amount of information are sought (Lambert \& Loiselle, 2007). To start off, personal factors that have been examined in relation to health information seeking include psychological variables such as anxiety (Eastin \& Guinsler, 2006), sociodemographic characteristics such as gender, educational level and age (e.g. Czaja, Manfredi, \& Price, 2003), and personality characteristic such as internal locus of control (Hashimoto \& Fukuhara, 2004) or preferences to be involved in health-related decision-making. For instance, women, younger and more educated individuals with a preference to be more involved in making decisions related to their health (Czaja et al, 2003) are reported to be active information seekers compared to others. 
Going beyond personal characteristics and factors, contextual or situational factors focuses more on individuals' ecological system, the context in which they seek information and the source of information. For instance, in a study examining twelve women who have breast cancer and their health information management, many of the participants reported feeling relieved, hopeful, supported, or distressed as they share, receive and exchange information from significant others in their lives, such as family and friends (Loiselle, Lambert, \& Cooke, 2006). Considering variation and interactions between individual, personal factors along with contextual variables, this further illustrates the complexity of HISB and how changeable it might be particularly when the environmental context has changed

Lambert and Loiselle (2007) reviewed past studies that have examined how HISB influences health-related outcomes and reported that individuals have generally reported positive outcome in cognitive, behavioral, and affective aspects of their lives. For instance, after seeking information, individuals may report more positive cognitive outcomes such as increased knowledge and perception of control related to health, increased in ability to make informed decisions, and coping. Individuals might also endorse an increase in behavioral outcomes related to health management, such as being able to discuss information they obtained with health professionals, better able to take care of themselves as well as increased adherence to treatment. Lastly, they might also experience positive emotions after seeking health information, such as increase hope, or a decrease in negative affect such as anxiety, fear and distress. However, in contrast to these studies with findings of positive outcomes related to health information search, some individuals who have sought information have reported having experienced 
negative emotions such as increased worry and feeling overwhelmed in comparison to their "information avoiding" counterparts. What Lambert and Loiselle (2007) speculated is that these outcomes might be potentially dependent on if there were discrepancy between the information seeking individuals were expecting to find and what they actually end up obtaining. This further emphasizes the importance of examining the context in which information is sought and obtained as well as how this might correspond with the information seeker's needs and ability to do something about the information they obtained.

The relationship between health information seeking and other aspects of health such as health literacy has been examined. For instance, in a sample studying Taiwanese adults, high health literacy is associated with the use of Internet as well as printed sources of information, versus those with limited health literacy were more likely than their higher literacy counterparts to seek health information from medical professionals directly or seek alternative care medicine providers who may or may not have been professionally trained (Wei, 2014). Given that health information seeking is highly dependent on situation and context, for adults living in Taiwan who have access to universal health care, the financial cost of seeking professional opinions from a medical provider is relatively low compared to U.S., there is little information currently to indicate how individuals' health seeking might look differently when the cultural context of healthcare has changed.

Over the years, researchers have been exploring HISB across different discipline as well as diverse health care contexts, such as a recent illness diagnosis, chronic disease management, as well as the high risk and clinic-based groups. However, there is still not 
a well-developed measure of HISB due to the complexity of the construct and the diversity of potential target populations. Currently, the most common approaches to measure health information seeking behavior include 1) using questions from the Health Information National Trends Survey (HINTS), 2) recording of key strokes /keylogging while individuals use online information services, 3) a general single item measure, and 4) a general multiple-item measure (e.g. Consumer Health Informatics Research resource (CHIRr; Hensel, Leshner, \& Logan, 2010).

As indicated previously, the Health Information National Trends Survey (HINTS) is one of the most common surveys used to measure health information seeking behaviors. HINTS was originally developed by National Cancer Institute (NCI), which aims to further research in health communication and health promotion while informing relevant programs, policies, and practices across various settings (Nelson et al., 2004). Considering that the wide use of HINTS survey by health information and health communication researcher (Tian \& Robinson, 2006; Ye, 2014; Chan, 2015), HINTS data has been analyzed to more effectively understand how adults in U.S. use different communication channels, including the Internet use, to obtain vital health information for themselves and loved ones. Moreover, researchers have conducted research studies using HINTS to continuously explore how health-related needs and communication practices have changed, while also using HINTS to test out new theories in health communication. Out of available instruments related to health information and behaviors, it is considered to be one of the most nationally representative survey tools measuring how people access and use health information. 


\section{Internet Usage and Health Information Seeking Behaviors}

With the advent of digital era, Internet has become a popular, convenient, mainstream searching tool changing the way individuals seek information and problemsolve in everyday living. According to an online report about Americans' Internet access from Pew Research Center (Perrin \& Duggan, 2015), over 84\% of American adults use the Internet, and adults with at least a college degree are the most likely to use the Internet, representing nearly $80 \%$ of total Internet users. Across various ethnicity groups in the U.S., Asian Americans were the most likely to use Internet (97\%) as compared to any other ethnicity groups (ranging from $78 \%, 81 \%$, to $85 \%$ for Black, Hispanic and White respectively). This number may not be exclusive to Asians living in the U.S., as the number of Internet users in Asia had experienced a huge growth right after the broadband Internet was introduced. Today, so while there are only $45.7 \%$ of Asians who access the Internet, there are $80 \%$ to $92 \%$ people in Hong-Kong, Japan, Singapore, South Korean and Taiwan who are Internet users. In addition, there are nearly $50 \%$ of people in China have Internet access (Miniwatts Marketing Group, 2015), which translates into six hundred and seventy-four million users. Up to $95.7 \%$ of people in Hong Kong uses the Internet to search for information. These data reflect the popular use of Internet for Asians, where searching online has become a part of their daily lives.

Since majority of East Asian international students are from countries with higher prevalence of Internet usage, many, if not most, of them may already familiar with using Internet as their main searching tool for finding information and resources. While there are no current statistics available, following the logic of if there are more than $75 \%$ of American Internet users go online looking for health information, and people living in the 
East Asian countries listed above use Internet more frequently, when it comes to healthrelated issues, it is likely that international students from Asian would probably use Internet as their "go-to" source to search for health information related to their concerns before seeking medical attention from physicians or health professionals. However, we cannot simply confirm hypotheses by directing translating HISB of American Internet users to those of Asian international students'.

While there have been other studies related to Internet usage conducted on international students studying abroad across the world, currently, there is very little empirical data on international students studying in the U.S. and specifically how their Internet HISB impacts their health. In one relevant study conducted by Ye (2005) over a decade ago, the results indicated that international students in the U.S. primarily use the Internet for the purpose of information seeking, followed by relaxation/entertainment and then social utility. Based on Ye's findings regarding consider different types of Internet usage motives among international students, he also suggested it is important that more research investigate the role the Internet plays in students' acculturative stress process.

Not only Internet has been shown to be a popular avenue of information seeking and support amongst East Asian international students, using Internet for information seeking and emotional support appeared to be beneficial psychologically for international students while studying abroad. Examined Chinese international students' use of online support groups, Ye (2006) found that for those who used online ethnic support groups and receive higher levels of informational and emotional support tend to experience lower levels of acculturative stress. For East Asian international students in particular, in a previous study where their general pattern of online information seeking behavior was 
examined in the context of acculturation, acculturative stress was not linked to general information seeking (Ye, 2005). Even if acculturative stress did not seem to be predictive of information searching behavior, it would be interesting to explore how changes in other aspects of psychological stress during cross cultural transition, such as anxiety, may be linked to their "motivation to go online", such as information seeking. Thus, to bridge the gap in the literature, this study seeks to better understand how Internet use, specifically HISB, relates to aspects of international students' adjustment in the U.S.

Out of the various types of health information that individuals seek, Cheong (2007) indicated that online health information has become as an important health information resource. Particularly, Internet health information has been suggested to be a crucial construct in influencing personal health management, and consequently improving health and increasing quality of life. Findings from past research studies have indicated that individuals who strived to deal with stressful health challenges were strongly motivated to engage in Internet HISB (Bowem, Ludman, Press, Vu \& Burke, 2003).

Internet usage has been linked with health information and decision-making. According to Pew Research Center's Internet \& American Life Project, 72\% of American Internet users have gone "online" and sought the Internet for some type of health information ranging from general health issues, health insurance, to specific disease or medical problems, within the past 12 month (Fox, 2008). While majority of Americans (70\%) received information, care or support related to their health from medical professionals, out of the $81 \%$ of U.S. adults who use the Internet, $72 \%$ of these users, seek general health information online, which translates to more than 100 million 
Americans (Pew Research Center, 2012). It is worth noting that Internet users not only conducted online health-related searches for themselves, but for their loved ones as well. For instance, $39 \%$ of U.S. adults were caregivers and $72 \%$ of them gathered health information online, particularly about medical problems, treatments, and drugs (Fox, Duggan, \& Purcell, 2013).

Not only has the number of "online health information seekers" increased over the years and is expected to continue to grow in the future, the act of searching for health information on the Internet impacts individual's decision-making process related to health. This is evident by one in three (35\%) of Americans have searched online to figure out a medical condition, while $53 \%$ of these adults shared that they talked with a medical professional about what they found online, according to data from Health Online 2013 by Pew Research Center's Internet \& American Life Project (Fox \& Duggan, 2013). This is similar rate, or perhaps even reflect an increase, of using health information to guide medical decisions, compared with previous results from World Health Organization (WHO) eHealth survey in 2008, where $29 \%$ of people use information from the Internet to decide whether they needed to see a doctor, and of those that did seek medical consultation or treatment, one in four used the Internet in conjunction with doctor's appointment (Sørensen, 2008).

One issue that may be problematic with the increase of health-related Internet searches is the lack of mechanism to filter and evaluate the quality and accuracy of information obtained on the Internet. This problem is two-fold; first, majority of online health seekers (approximately 85\%) do not check their source of information, and second, health-related websites are not held accountable for the information they distribute. 
According to a study conducted under the direction of U.S. Department of Health and Human Services (2006), out of the health-related websites surveyed, less than five percent publish dates their content was created, whereas only $3 \%$ show when their content was updated, which leaves Internet users unable to double-check the source of their information. This is consistent with previous studies that show over $70 \%$ of studies reviewing and evaluating online health information reported problems in the quality of information provided through the Internet (Eysenbach, Powell, Kuss, \& Sa, 2002). Not only might "online health information seekers" be misinformed, it might have further negative implications for those who might have a disposition to be anxious or "health anxious".

Health anxiety has been found to moderate the relationship between online health information and health care utilization decisions (Eastin \& Guinsler, 2006). Moderately anxious individuals were more likely to seek higher amounts of online health information and make medical decisions such as obtaining appointments for medical professions, while their lower-anxiety counterparts were less likely to visit a doctor after their search for information online. Also, it has been said that health anxious individuals experience more negative consequences from online health information search, although researchers also have posited that online health information results in greater worries among health anxious individuals, compared to non-health anxious individuals, only if the information stems from a trustworthy governmental website (Baumgartner \& Hartmann, 2011). Thus, understanding how international student's anxiety and satisfaction with life might be related to their HISB is crucial to understanding their adjustment and overall well-being in the U.S. 


\section{Health anxiety}

Health anxiety has been operationalized as "concern about health in the absence of a pathology or excessive concern when there is some degree of pathology" (Lucock \& Morley, 1996, p 137). Similar to other types of anxiety, one way to alleviate intensity or existence of its symptoms is to take some type of action, such as seek out more information to find out whether it warrants further action or there is simply not enough to worry about.

In addition to physical health issues, mental health related problems were also evident among this group of international students, particularly with the issue of struggling with anxiety (Rosenthal, Russell, \& Thomson, 2008), even more so than depression or stress. While anxiety in particular appeared to be heightened in this population, as anxiety appeared to be highly correlated independently with depression and stress, it is easy to see how a heightened sense of anxiety might impact overall wellbeing with its high correlations with the other two factors. Out of that sample, Asian students tend to score higher on anxiety than non-Asian students.

The Theory of Motivated Information Management (TMIM; Afifi \& Weiner, 2004) may serve as a fitting conceptualization model linking anxiety with information seeking. Divided into three hierarchical phrases, namely, Interpretation, Evaluation, and Decision, the first phrase of the theory includes the premise that as uncertain or discrepancy arises, anxiety ensues. Using Brashers's (2001) definition of uncertainties, which includes "details of the situation are ambiguous, complex, unpredictable, or probabilistic; when information is unavailable or inconsistent; and when people feel insecure in their own state of knowledge or the state of knowledge in general" (p. 478). 
Within TMIM, Afifi \& Weiner (2004) proposed that "discrepancy activates anxiety and that individuals are motivated to manage the physiological reaction of anxiety" (p. 174), which lead them to posit that the both the uncertainty discrepancy and the anxiety that ensued are the main component in initiating the process of information management and seeking. In other words, they assume that individuals manage anxiety by seeking information. While this assumption is an important underpinning drive for TMIM, Afifi \& Weiner (2004) also recognize individual differences of how individuals cope in response to anxiety. Other possible responses in addition to seeking information includes avoiding relevant information, cognitive reappraisal by making psychological adjustment to deal with the original anxiety that activated the need for information. Thus, applying this theory and its concepts to current study, it is plausible that anxiety may drive the need for information search or avoidance, and consequently impact other aspects of an individual's life and well-being.

Related to health anxiety management, one way of coping with such anxiety is to seek information online first and take further action such as seek medical treatments. Particularly as the Internet been identified as one of the most common and widely used sources for health information (Atkinson, Saperstein, \& Pleis, 2009), there has been empirical evidence of linking the level of anxiousness with the amount of online health information sought, as well as the likelihood of individuals seeking professional help. For instance, moderately or highly anxious individuals were more likely to seek higher amounts of online health information and make more action-oriented medical decisions (e.g. obtaining appointments for medical professions), while those with lower anxiety are much more likely to stop after searching for information on the Internet. 
While the convenience, efficiency, accessibility and information availability of the Internet Information Seeking have been expanding at an astonishing speed, individuals have also commented on the overwhelming feeling of "Information overload", which may lead to dysfunctional consequences such as anxiety. At times, the Internet is not only used to search for health information, but also being used by individuals as a diagnostic instrument, where common symptoms may be misinterpreted as the result of

more serious illnesses. Related to this increasingly common phenomenon, White and Horvitz (2009) coined the term "cyberchondria" to refer to "unfounded escalation of concerns about common symptomatology, based on the review of search results and literature on the Web" (p 23).

\section{Present study}

In conclusion, examining international students' online HISB may be crucial in understanding to their adjustment and well-being in the U.S. Furthermore, it is also essential to understand Asian international students' online HISB in order to provide accurate and reliable health-related information for healthcare providers while providing services. Therefore, this study sought to better understanding of Asian international students' online HISB, cross-cultural loss, anxiety and satisfaction with life. 


\section{CHAPTER III}

\section{METHODS}

The proposed study design was to examine Internet health seeking behavior, cross-cultural loss, anxiety, and satisfaction with life among East Asian international

students studying in the U.S. Specifically, one of the aims of this study was to identify what, if any, correlations exist between 1) anxiety and satisfaction with life, 2) anxiety and Internet health information seeking behavior, as well as 3) Internet health information seeking behavior and satisfaction with life. More specifically, this study intended to explore mediating role of Internet health information seeking behavior in the relationship between anxiety and satisfaction with life as well as the moderating role of cross-cultural loss in the relationship between Internet health information seeking behavior and satisfaction with life. By investigating the above questions, it is intended to shed light on health seeking behaviors among international students during their stay in the U.S. and how it may be connected to psychological distress and well-being.

\section{Participants}

During Spring 2016, international students who were currently studying in the U.S. with F-1 or J-1 visa at the time, originally from the following East Asian countries including China, Hong Kong, Taiwan, Japan, and South Korea, were eligible to participate in current study. After deleting surveys with excessive missing and incomplete data (e.g. participants who abandoned the survey before reaching the end and failed to complete two or more of the measures), a total of 186 surveys were collected. In determining desirable sample size when conducting path analysis, following Kline (1998)'s recommendation, the guideline is to have a sample size that is 10 (minimal) to 
20 (desired) times the amount of model parameters. As there are 6 parameters among the models examined in this study, 186 participants exceed the desired number of 120 participants.

Out of the 186 participants, there were 123 women and 56 men (4 participants indicated "prefer not to answer" as their response and 3 participants had missing responses when asked about gender). Mean age for the sample was $26.09(\mathrm{SD}=4.95)$. Majority of the participants were pursuing a graduate or professional degree (67\%). The average length of stay in the U.S. is 4.7 years. Participants were studying at various states across the United States, with Missouri (30.6\%) being where most participants were located, followed by Florida (7\%), Texas (5.9\%), California (5.4\%) and Ohio (5.4). The international students who indicated they were current studying in the state of Missouri within this sample are unrepresentatively high, when compared to where international students are located nationally. While most of recruitment advertisements were posted on Facebook groups of international student organization at different universities, as primary researcher attended University of Missouri, the international office on campus agreed to post an advertisement via their international student listserv to facilitate with recruitment, this might explain why close to a third of participants indicated that they are from Missouri.

A little more than half of the participants indicated that they were from Taiwan originally (53.8\%; $\mathrm{N}=100)$, followed by twenty-nine percent ( $29 \%, \mathrm{~N}=54$ ) from China, nine percent from South Korea $(9.1 \% ; \mathrm{N}=17)$ and the remaining of participants from Japan and Hong Kong (3.8\% and 2.7\% respectively). As the primary researcher is also an international student from Taiwan, this might account for why Taiwanese international 
students represent majority of the participants in current study, as more Taiwanese students might have identified with primary researcher being from the same country and thus were more willing to participate and complete the study. Also, while efforts were made to search for and post recruitment ad on international student Facebook group/page of the countries represented, due to primary researchers being a Taiwan international student, access to Taiwanese international student of various universities were granted more easily by web administrators than Facebook group/page of similar nature of the other countries.

\section{Procedure}

Participants were primarily recruited through Facebook, international student offices listserv, and word of mouth. They were told that this was a study about international students' health information seeking behavior, and they needed to be at least 18 years old to participate. Participants completed the surveys online, which was presented in English; the estimated time of completion for the survey is approximately 15 minutes or less. Incentives provided to participants included a chance to win a monetary gift in a drawing after survey completion (one of two $\$ 50$; one of four $\$ 25$; or one of thirty $\$ 10$ gift cards in a raffle). The survey also included two validity check items at each time point (e.g., Please simply select [Slightly agree] for this item). Participants who gave any incorrect responses on either of the two validity check items were deleted due to invalid responses.

Components of the study advertisement posted include the following (a) brief description of the study, including the eligibility criteria and approximate length of time required to complete the survey, (b) information regarding compensation for study 
participation, and (c) a web-based link connecting them to the survey web page. When clicked on the web link, participants would be taken to the informed consent statement where participants had the opportunity to read a brief description of the study and were informed of their right to decline or discontinue participation at any time in the research process without negative consequences. Similar to many online studies, because of the anonymous nature of the study, participants indicated consent by checking a box indicating that they have read and agreed to the consent form.

\section{Instruments}

Participants responded to several measures assessing the main study variables (three predictors [general anxiety and 2 types of health anxiety], one mediator [Internet health information seeking behavior, iHISB], one outcome variable [satisfaction with life], and one moderator [cross cultural loss]), as well as a demographic survey.

The Short Health Anxiety Inventory (SHAI: Salkovskis, Rimes, Warwick, \& Clark, 2002). SHAI (18-item) is a shortened version of the 64-item Health Anxiety Inventory (HAI). It was developed to assess health anxiety in both healthy and physically ill individuals. SHAI contains 14 items mainly to assess health anxiety independently, as well as the 4-item subscale measuring the perceived negative consequences of becoming ill. Each item of the SHAI consists of a group of four statements in which an individual selects the statement that best reflects their feelings over the past 6 months. Item scores are weighted 0-3 and are summed to obtain a total score. Internal consistency for the short-form of Health Anxiety Inventory (SHAI) was .89 (Salkovskis, et al., 2002). 
According to Alberts et al. (2013), there have been two ways to conceptualize and measure health anxiety using SHAI. One approach is to use the full scale of 18 -items of SHAI, while the other is to separate the main 14-item subscale from another subscale consisting of four items design to measure "perceived negative consequences of becoming ill" (Alberts et al., 2013, p 69). As this four-item subscale has been said that it does not directly measure health anxiety, past studies have argued for the exclusion of these items when measuring health anxiety and proposed to use solely the main 14-item subscale. For the purpose of current study, the full 18-item version of the short version of SHAI will be referred to as SHAI-18 and the 14-item main scale of the SHAI minus the 4-item perceived negative consequences subscale will be referred to as SHAI-14.

The short-form of Depression, Anxiety Stress Scale (DASS-21: Lovibond \& Lovibond, 1995). DASS-21 is a short form of the full 42-item measure of depression, anxiety and stress (DASS), which consists of three 7-item self-report scales. Items consist of statements about depression (e.g., "I felt life was meaningless"), anxiety (e.g., "I felt scared without any good reason"), and stress (e.g., "I found it hard to wind down"). Each item is scored on a 4-point Likert scale $(0=$ did not apply to me at all, to $3=$ applied to me very much or most of the time). Higher scores in DASS-21 indicate greater levels of distress. DASS-21 is not only a reliable measure, but also easy to administer for both clinical and research purposes. Previous research using DASS-21 among cross racial groups reported the internal consistency about each subscale ranged from .78 to .83 (Norton, 2007).

Internet Health Information Seeking Behavior (iHISB). This study will use two different scales to measure international students' online HISB. The first section will 
include 8 items adapted from multiple HINTS questionnaire (HINTS 2003, HINTS 2005, HINTS 2008, and HINTS 2011-2014) related to health information search on Internet (e.g., Internet use, health communication, health services, as well as medication and nutrition, etc). The Health Information National Trends Survey (HINTS) is considered one of the most nationally representative survey tools to measures how people access and use health information. The second section of the iHISB will use a recently developed questionnaire measuring amount of time participants spend obtaining health information online (Weaver et al., 2010). This 6-item questionnaire was developed to measure HISB search online by assessing participants "how much time" they spent "during a typical week" obtaining information related to 6 content domains: diet, exercise, disease or illness, medications, parenting and treatments. Reported correlation coefficients between the variables were ranging from .40 (parenting) to .88 (exercise), transformed with a base-10 logarithm to improve normality (Weaver et al., 2010).

The Cross-Cultural Loss Scale (CCLS: Wang, Wei, Zhao, Chuang \& Li, 2015). The CCLS scale is a 16-item measure designed to assess loss associated with crossing national boundaries and consists of 4 subscales, including Belongingness ( 4 items), Competency (4 items), National Privileges (4 items), and Access to Home Familiarity (4 items). Each item is rated on a 5-point Likert Scale ranging from 1 (not at all) to 5 (completely). Higher scores for overall scale and within each subscale represent the higher level of global loss and specific loss respective to each subscale. Internal consistency (Cronbach's Alpha) for the total scale and each subscale ranged from .72 to .90 (Wang, Wei, Zhao, Chuang \& Li, 2015). 
The Satisfaction with Life Scale (SWLS: Diener, Emmons, Larsen, \& Griffin, 1985). SWLS is a 5-item measure to assess the general level of life satisfaction. Each item is rated on a 7-point Likert scale ranging from 1 (strongly disagree) to 7 (strongly agree). Higher scores indicate higher satisfaction with Life. The Cronbach's Alpha was reported to be .86 in a sample of international students (Wei, Wang, \& Ku, 2012).

Demographic Questionnaire. A demographic questionnaire included inquiries about participants' age, education level, gender, marital status, nationality, length of time in the U.S., past experience of living or studying in the U.S., English testing score (e.g., TOEFL: Test of English as a Foreign Language, or IELTS: International English Language Testing System), as well as their current health insurance information (e.g., health insurance enrollment status, health insurance plan and premium, etc.), and questions related to Internet use (e.g., "what kind of electronic devices do you have?", "where do you access to Internet most often?" and "what type of Internet access you have?").

\section{Data Screening}

There were originally 386 international students/scholars participated in this study. After removing 198 incomplete, invalid or not eligible cases, a total of 188 cases were kept for examining missing value and outliers. Little's Missing Completely at Random test $(\mathrm{MCAR})$ on SHAI $\left(\mathrm{X}^{2}=41.392, \mathrm{df}=42, \mathrm{p}=.498\right)$ and $\mathrm{iHISB}\left(\mathrm{X}^{2}=28.360, \mathrm{df}=23\right.$, Sig. $=.202)$ are not significant. Therefore, random missing values at the item level could be replaced through the Expectation-Maximization Method before summing subscale scores. Univariate outliers were examined and screened with Z-scores $\geq|3.29|$. Two cases were deleted due to containing an univariate outlier each. Using the criterion of $\chi^{2}$ 
$(2)=13.82, \alpha=.001$, no multivariate outlier was identified. As a result, a total of 186 cases were retained for further data analysis. 


\section{CHAPTER IV}

\section{RESULTS}

\section{Preliminary Analysis}

Preliminary analysis was processed through IBM SPSS Version 22. Descriptive statistics of the demographics variables are shown below in Table 1. Among all 186 participants, three completed the entire survey with the exception of demographic information at the end. After excluding the three participants, out of the remaining 183 participants, 123 participants $(67.2 \%)$ identified themselves as females and 56 participants (30.6\%) identified themselves as males, the remaining four indicated that they prefer not to reveal their gender identity. Out of 181 participants who reported their age, ranged from 18 to 45 years old, the majority (93 participants, 50.8\%) indicated that they were between the age of 25 to 34 , followed by 77 participants $(42.1 \%)$ who were between the age of 18 to 24 . There were 151 participants (82.5\%) claimed to be single, while other 29 participants $(15.8 \%)$ were either married or in a domestic partnership.

Among the 183 participants, there were 155 participants $(83.3 \%)$ currently enrolled as full/part time student (F-1 visa), while others were either on Optional Practical Training (OPT) visa (13 students; 7\%) or visiting scholar, J-1 visa (15 students; 8.1\%). Majority of them were pursuing a post baccalaureate degree, with 63 participants (34.4\%) pursuing their doctoral degree and 54 participants $(29.5 \%)$ pursuing master degree, while other 49 participants $(26.8 \%)$ are currently completing their undergraduate degree. Over half of the participants (54.6\%) came from Taiwan, with the second largest group of 54 participants $(29.5 \%)$ identifying that they were originally from China, and 17 participants. 
Table 1

Demographic Descriptive Characteristics

Variable

Age group

$18-24$

25-34

$35-44$

45-54

Gender

Male

Female

Prefer not to answer

Marital Status

Single/ Never married

Married/ Domestic partnership

Divorced

Prefer not to answer

Degree pursuing

Undergraduate

Master

Doctoral

Professional (JD, MD, etc.)

Non-degree seeking

Others

Place of Origin

China

Hong Kong

Japan

South Korea

Taiwan

Visa Status

F-1

OPT

J-1

Language use for iHISB $^{b}$

English

Native language

Note. $\mathrm{N}=186$ (system missing=3)
Respondent (\%)

$77(42.1)$

$93(50.8)$

10 ( 5.5)

$1(0.5)$

$56(30.6)$

$123(67.2)$

4 ( 2.2)

$151(82.5)$

29 (15.8)

$1(0.5)$

2 ( 1.1$)$

49 (26.8)

54 (29.5)

63 (34.4)

6 ( 3.2$)$

$10(5.5)$

$1(0.5)$

$54(29.5)$

5 ( 2.7)

7 ( 3.8)

17 ( 9.3)

100 (54.6)

$155(83.3)$

$13(7.0)$

15 ( 8.1)

62 (33.9)

$121(66.1)$

(9.3\%) from South Korea. Among all 186 participants, 89 participants (47.8\%) claimed that they did not have doctor's visit during the past 6 months, while others $(51.4 \%)$ reported having at least one time visit to their doctor's office (Table 2). 
Descriptive statistics of the observed variables in Table 2 showed that there were over $82.9 \%(\mathrm{~N}=153)$ of the participants reported that they have either searched illness $(12 \%, \mathrm{~N}=12)$, wellness $(16.7 \%, \mathrm{~N}=31)$ or both illness and wellness combine health related information online in the past 6 months in this study. With 183 participants having reported language usage while searching health related information online, more than two-third of the participants $(66.1 \%, \mathrm{~N}=121)$ preferred to use their native language searching health related information online than English (Table 1). Other statistic result of the study variables such as Means, standard deviations, and alpha coefficients of the study variables are presented in Table 4 . The internal consistency of study variables was good with Cronbach's alphas above .80, except Anxiety Subscale of Depression, Anxiety Stress Scale (DASS-A) was acceptable $(\alpha=.79)$.

Participants' perception of their language proficiency was also assessed in the demographic survey. As there are many different English proficiency tests available, Test of English as Foreign Language (TOEFL) is generally the most common test international students tend to take and is widely accepted across U.S. institutions when evaluating admissions for incoming international students. If participants reported that they took a test other than the TOEFL, scores were converted accordingly for standardization purposes. Similarly, as there were different versions of the TOEFL, including the earliest version of Paper-Based Test (PBT), Computer-Based Test (CBT), to the most recent and updated version of Internet-Based Test (iBT), if students had taken the two previous versions of TOEFL, namely PBT or CBT, their scores were also converted to the iBT equivalent for accurate analyses. The iBT, in particular, has four sections to assess English language proficiency, namely reading, listening, speaking and 
writing, with 30 possible points to be obtained for each section, a total 120 possible points for the overall assessment. Within this study, the average iBT score of participants' was 82.4 out of 120 .

A Chi-square test was performed to test the association between English and native language usage while searching for health-related information through Internet among East Asian international students. International students who performed healthrelated search on the internet (e.g. information related to either illness or wellness of health-related information) prefer to use their native languages than English. There were $69.9 \%$ of international students use their "native language" compare with the other $30.1 \%$ using English while searching health related information on the Internet. There was a significant difference between language usage and Internet health-related Information Seeking $\left(X^{2}(1)=4.66 p<.05\right)$. In addition, the Chi-square test was also performed to test the relationship between gender and Internet Health Information Seeking Behavior. Result indicated that there was no relationship between gender and Internet Health Information Seeking Behavior $\left(X^{2}(2)=1.60, p=.412\right)$. Furthermore, Chi-square was performed to test the relationship between gender and English and native language usage as well. However, the difference was not significant $\left(X^{2}(2)=.57, p=.765\right)$. Thus, there was no relationship between gender and language usage while using the Internet to search health-related information among East Asian international students.

In terms of their general anxiety, more than half of the participants reported "normal" level of anxiety (50.5\%), followed by nearly a quarter of the participants indicating that they endorse "moderate" anxiety (24.2\%), with the remaining participants split relatively similarly into "mild "( $(9.7 \%)$, "severe" $(8.1 \%)$, and "extremely severe" 
(7.5\%) levels of anxiety, respectively (Table 2 ).

Table 2

Percentage Distribution of Health-Related Variables

\begin{tabular}{lr} 
Variable & Respondent (\%) \\
\cline { 2 - 2 } iHISB & \\
No search & $33(17.1)$ \\
Illness Only & $12(6.5)$ \\
Wellness Only & $31(16.7)$ \\
Search for Both & $110(59.1)$ \\
Anxiety Level (DASS-A) & \\
Normal & $94(50.5)$ \\
Mild & $18(9.7)$ \\
Moderate & $45(24.2)$ \\
Severe & $15(8.1)$ \\
Extreme Severe & $14(7.5)$ \\
Doctor's visit (past 6 months) & $a b$ \\
None & \\
1 time & $89(47.8)$ \\
2 time & $30(16.1)$ \\
3 time & $32(17.2)$ \\
4 time & $20(10.8)$ \\
$5-9$ time & $3(1.6)$ \\
10 time or more & $7(3.8)$ \\
\hline
\end{tabular}

Note. $\mathrm{N}=186, \mathrm{iHISB}=$ Internet Health Information Seeking Behavior

a. not counting the times of going to an emergency room

b. $\mathrm{N}=183$

The frequency of overall participants' online health information searches, assessed by HINTS, was presented in Table 3. It was further separated into four subquestions. The first and second question assessed for their overall frequency of searching for health or medical information for themselves or someone else, respectively. Third question was related to how frequently they discuss health information they obtained from the internet with a health professional, such as a doctor, nurse or other types of health professionals. The last question was regarding how frequently they read information on Internet related to health unintentionally, without actively searching for it. 
Using the time frame of the past six months, participants had the option of selecting “once a week", “once a month", "every few months", or "less often [than every few months]". Simply judging by frequency, it would appear that participants within this study do search for health information online, but not many of them search for it frequently as majority of them seem to do so only "every few months" or "less often".

\section{Primary Analysis}

Exploring the relationship between anxiety and Internet health information seeking behavior (iHISB) in hypothesis 1, it was originally hypothesized there is a significant, negative relationship between anxiety (both general and health anxiety) and satisfaction with life (SWLS). As previously mentioned, according to Alberts et al. (2013), there were two ways of conceptualizing and measuring health anxiety by using short version of the Health Anxiety Inventory (SHAI). One approach used the full scale of 18-items of SHAI, while others only used the main 14-item subscale by dropping the other 4-item subscale designed to measure "perceived negative consequences of becoming ill" (Alberts et al., 2013, p 69). Bivariate correlations result in Table 4 showed a significant, negative association between overall health anxiety (SHAI-18) and SWLS $(r=-.175, p=.017)$, as well as a significant, negative association between general anxiety (DASS-A) and SWLS ( $r=-.202, p=.006)$. In this instance, hypothesis 1 was supported, as originally expected, the higher an individual's anxiety, the lower their wellbeing will be. However, it should be noted that when only conceptualizing health anxiety using SHAI-14 with the 14-item main scale, there is no significant association between health anxiety (SHAI-14) and satisfaction with life (SWLS) $(r=.142, p=.054)$. 
Table 3

Frequency of Internet Health Information Seeking Behavior

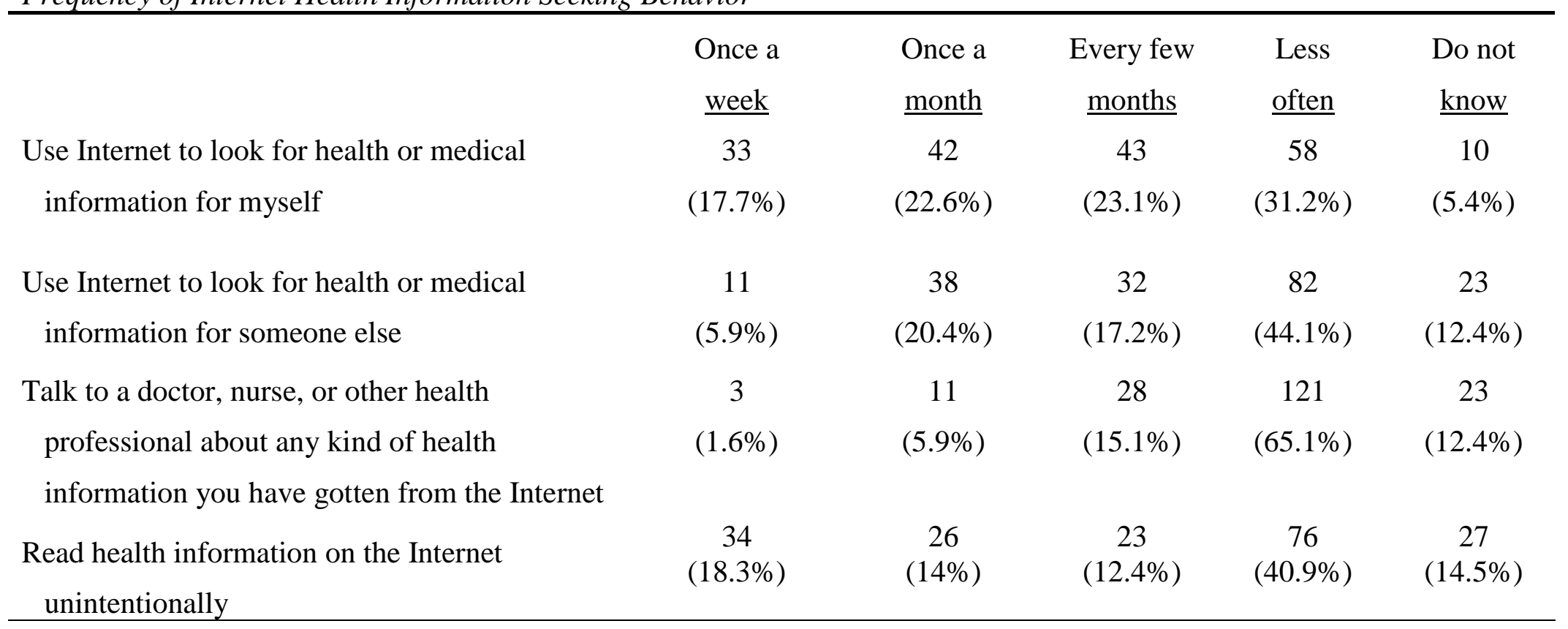

Note. $\mathrm{N}=186$ 
In hypothesis 2 , it was hypothesized that there is a significant, positive relationship between anxiety and Internet health information seeking behavior (iHISB). Bivariate correlations result presented in Table 4 showed that neither overall health anxiety (SHAI-18, $r=.139, p=.059$ ) nor general anxiety (DASS-A, $r=-.117, p=.112$ ) were associated with Internet health information seeking behavior (iHISB) in this study. Based on the results above, hypothesis 2 would be rejected, as there is no positive, significant relationship between general or health anxiety and Internet health information seeking behavior. However, if health anxiety is measured by using SHAI-14, there is a positive association between health anxiety (SHAI-14) and Internet health information seeking behavior $(\mathrm{iHISB})(\mathrm{r}=.152, \mathrm{p}<.05)$.

In hypothesis 3, it is hypothesized that Internet Health Information Seeking Behavior will mediate the relationship between anxiety and satisfaction with life. Figure 1 and 2 are the visual representations of the hypothesized mediation models used within this study; the two models are identical except the predictor used are different. Figure 1 is testing the mediating role of iHISB in the relationship between general anxiety, measured by anxiety subscale in DASS and satisfaction with life, whereas the predictor variable in the model in Figure 2 is replaced by health anxiety, measured by SHAI. Before proceeding with Hypothesis 3, there were a few considerations to note prior to conducting mediation analyses. Traditionally, in order to establish mediation, there are four steps that need to be met in order to indicate complete mediation, or at least the first three steps need to be met to fulfill the criteria of a partial mediation (Baron \& Kenny, 1986; Kenny, Kashy, \& Bolger, 1998). For the hypothesized mediation model in this study, step 1 would be to show that causal variable, anxiety in this case, is correlated with 
the outcome variable, which is satisfaction with life (shown in the results of hypothesis 1). General anxiety (DASS-A) and overall health anxiety (SHAI-18) meet this criterion as they are both correlated with satisfaction with life, but not main scale of health anxiety (SHAI-14). To fulfill Step 2, the causal variable, anxiety, would need to be correlated with the mediator, Internet health information seeking behavior (iHISB). Evidence in the results for hypothesis 2 , the only anxiety variable that meets this criterion would be SHAI-14, and not general anxiety (DASS-A) or overall health anxiety (SHAI-18).

While none of the variables met both step 1 and step 2, according to Kenny, Kashy and Bolger (1998), step 1 is not required if step 2 and step 3 are met, as the path from the initial variable to the outcome variable is implied. This is consistent with Hayes's (2009) argument that it is still possible for predictor variable (X) to exert an indirect effect on outcome variable (Y) through a mediating variable in the absence of an association between $\mathrm{X}$ and $\mathrm{Y}$. With this in mind, only SHAI-14 as the initial variable met the test in step 2, thus step 3 was conducted with SHAI-14, and not the other two predictor variables (e.g. SHAI-18 and general anxiety). To elaborate further, step 3 is to show that mediator affects the outcome variable by using SWLS as the criterion variable in the regression equation and both anxiety (SHAI-14) and Internet Health Information Seeking Behavior (iHISB) as the predictors. By doing so, a significant regression was found through the multiple-linear regression $(\mathrm{F}(2,183)=4.331, \mathrm{P}<.05)$, with an $R^{2}$ of .045. In other words, the effects of mediator iHISB on SWLS is established while controlling for anxiety (SHAI-14). With SHAI-14 having met criteria for both step 2 and 3 , next steps is to proceed to test mediation and moderated-mediation analyses using 


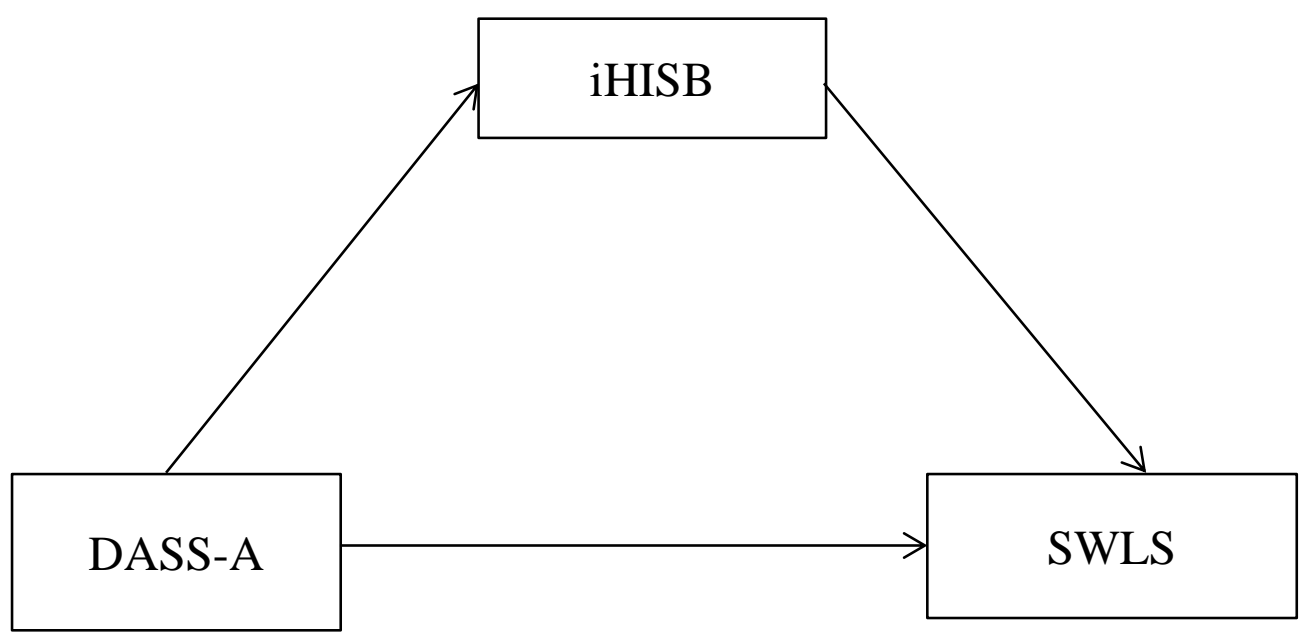

Figure 1. Hypothesized mediation model examining mediating effect of iHISB on DASS-A and SWLS

Note: DASS-A= Anxiety Subscale of Depression, Anxiety Stress Scale, iHISB=Internet Health Information Seeking Behavior , and

SWLS=Satisfaction with Life Scale

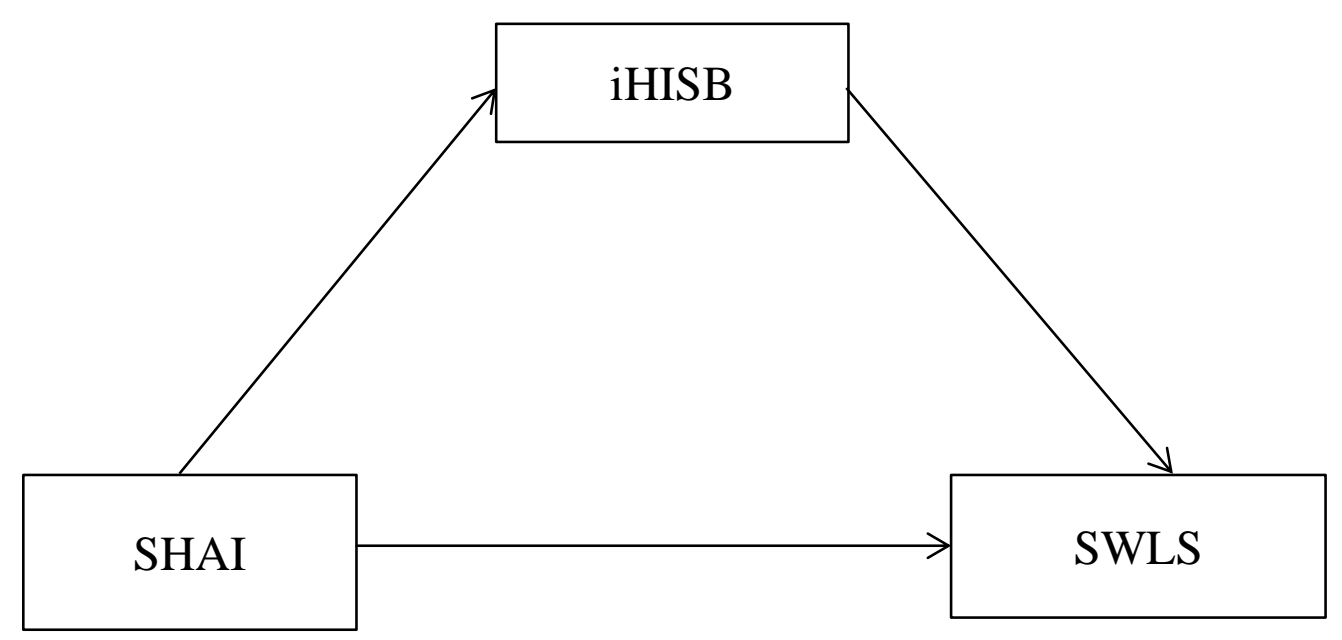

Figure 2. Hypothesized mediation model examining mediating effect of iHISB on SHAI and SWLS

Note: SHAI=Short form of Health Anxiety, iHISB=Internet Health

Information Seeking Behavior, and SWLS=Satisfaction with Life Scale 
Table 4

Bivariate Correlation, Mean, Standard Deviation and Alpha Coefficient of the Study Variables

\begin{tabular}{|c|c|c|c|c|c|c|c|c|c|c|c|}
\hline & 1 & 2 & 3 & 4 & 5 & 6 & 7 & 8 & $\bar{M}$ & $\mathrm{SD}$ & alpha \\
\hline 1. SWLS & - & & & & & & & & 23.09 & 5.78 & .88 \\
\hline 2. CCLS & $-.259^{* *}$ & - & & & & & & & 44.34 & 9.94 & .88 \\
\hline 3. SHAI-18 & $-.175^{*}$ & $.274^{* *}$ & - & & & & & & 25.17 & 14.77 & .91 \\
\hline 4. SHAI-14 & -.142 & $.248^{* *}$ & $.952^{* *}$ & - & & & & & 18.60 & 12.04 & .89 \\
\hline 5. DASS-A & $-.202^{* *}$ & $.249^{* *}$ & $.274^{* *}$ & $.289^{*}$ & - & & & & 8.54 & 6.67 & .79 \\
\hline 6. iHISB & .135 & -.099 & .139 & $.152^{*}$ & -.117 & - & & & 2.17 & 1.16 & .89 \\
\hline 7. PCS & .042 & -.096 & $-.267^{* *}$ & $-.306^{*}$ & $-.198^{*}$ & $-.171^{* *}$ & - & & 54.10 & 6.12 & .84 \\
\hline 8. MCS & $.360^{* *}$ & $-.156^{*}$ & $-.245^{* *}$ & $-.233^{*}$ & $-.384^{* *}$ & $.156^{* *}$ & $-.245^{* *}$ & - & 44.32 & 9.75 & .84 \\
\hline
\end{tabular}

Note. ${ }^{*} p<.05^{* *} p<.01$

SWLS=The Satisfaction with Life Scale; SHAI-18=Health Anxiety Inventory (full scale); SHAI-14=Health Anxiety Inventory (main scale with 14 items); DASS-A= Anxiety Subscale of Depression, Anxiety \& Stress Scale; iHISB=Internet Health Information Seeking Behavior; PCS= Physical Component Summary Scores; MCS=Mental Component Summary Scores 
PROCESS (Hayes, 2013), a macro for SPSS developed to test mediation and moderatedmediation analyses.

Recommended as the method of choice for testing indirect effects (Hayes, 2009), PROCESS has claimed to have has advantages over other approaches, such as the causal steps approach (Baron \& Kenny, 1986) or the Sobel test (Sobel, 1982). PROCESS provides bootstrap estimates to calculate bias-corrected confidence intervals for the mediation and moderated-mediation effects. Through PROCESS, the estimation accuracy of the indirect effects is strengthened, as the procedure involves resampling multiple times and estimating the sampling distribution from all the resamples (Preacher \& Hayes, 2008). For this study, the estimated mean of $95 \%$ confidence intervals (CI) of indirect effects derived from 5,000 bootstrap samples. If the upper and lower bounds of the CI do not include zero, then the presence of an indirect effect can be concluded with $95 \%$ confidence.

Specifically, for this study, with the intention of examining the mediation in hypothesis 3, PROCESS model 4 was used to examine whether or not the Internet health information seeking behavior (iHISB) mediate the relationship between health anxiety (SHAI-14) and satisfaction with life (SWLS). For Hypothesis 3, this study followed the same method to examine the indirect effect of iHISB on the relation between SHAI-14 and SWLS. Bootstrapping estimates indicated that iHISB mediated the link between SHAI-14 and SWLS [95\% CI (.0005, .0386); indirect effect $=.012$, S.E. $=.009, Z=$ $1.433, p=.152 ;$ total effect $=-.068$, S.E. $=.035, t=-1.943, p=.054$; direct effect $=-.080$, S.E. $=.035, t=-2.273, p=.024]$. Result of the bootstrapping estimates in Table 5 have shown that the true indirect effect was estimated to lie between .0005 and 0.0386 with 
95\% confidence intervals (bias corrected $[\mathrm{BC}] 95 \% \mathrm{CI}[.0005, .0386])$. Since zero was not included in the $95 \%$ confidence interval, it is concluded that the indirect effect is significantly different from zero at $p<.05$. Hypothesis 3 was supported that Internet health information seeking behavior mediate the relationship between health anxiety and satisfaction with life. International students' satisfaction with life, in response to their health anxiety, was mediated through Internet health information seeking behavior. The results indicated that higher levels of health anxiety are associated with higher levels of Internet health information seeking, which in turn are associated with lower levels of satisfaction with life.

Table 5

Regression Results for Mediation: SHAI-14 $\rightarrow$ iHISB $\rightarrow S W L S$

\begin{tabular}{lcccc}
\hline Predictor & $B$ & $S E$ & $t$ & $p$ \\
\hline Constant & 22.834 & 1.033 & 22.098 & .000 \\
iHISB & .799 & .364 & 2.193 & .030 \\
SHAI-14 & -.080 & .035 & -2.273 & .024 \\
\hline \multicolumn{1}{l}{ Indirect effect } & Effect & Boot $S E$ & \multicolumn{2}{c}{$95 \%$ CI } \\
\hline
\end{tabular}

Note. $\mathrm{N}=186 . R^{2}=.031$. All $p$ values, two-tailed; $\mathrm{CI}=$ confidence interval SWLS=The Satisfaction with Life Scale; SHAI-14=Health Anxiety Inventory 14item main; iHISB=Internet Health Information Seeking Behavior.

To test the moderated-mediation in hypothesis 4 , it was hypothesized that crosscultural loss (CCLS) will moderate the relationship between Internet health information seeking behavior (iHISB) and satisfaction with life (SWLS) shown in Figure 3. With Cross-Cultural Loss (CCLS) as a moderator, it might strengthen the association between Internet health information seeking behavior (iHISB) and satisfaction with life (SWLS); it was originally assumed that for international students who experienced greater sense of 
loss, the more health information they seek and obtain, the lower their satisfaction with life will be.

Using PROCESS macro model 14 to process the analyses for the moderated mediation, bootstrapping results were presented in Table 6 . The interaction between Cross-Cultural Loss (CCLS) and Internet Health information seeking behavior (iHISB) on predicting Satisfaction with Life (SWLS) was not significant $(B=-.020$, S.E. $=.038, t$ $=-.511, p=.61)$. Hypothesis 4 was rejected. Thus, Cross-Cultural Loss (CCLS) did not moderate the association between Internet health information seeking behavior (iHISB) and satisfaction with life (SWLS).



Figure 3. Hypothesized moderated-mediation model:

Note: SHAI=Short form of Health Anxiety, iHISB=Internet Health

Information Seeking Behavior, CCLS=Cross-Cultural Loss, and

SWLS=Satisfaction with Life Scale 
Table 6

Regression Results for Conditional Indirect Effect:

SHAI-14 $\rightarrow$ iHISB $\rightarrow$ SWLS (Moderator: CCLS)

\begin{tabular}{lrrrr}
\hline \multicolumn{1}{c}{ Predictor } & $\boldsymbol{B}$ & $\boldsymbol{S} . \boldsymbol{E} \boldsymbol{.}$ & $\boldsymbol{t}$ & $\boldsymbol{p}$ \\
\hline Mediator model (DV = iHISB) & & & & \\
Constant & -.272 & .169 & -1.612 & .109 \\
SHAI-14 & .015 & .007 & 1.984 & .049 \\
& & & & \\
Outcome model (DV = SWLS) & 24.017 & .807 & 29.756 & .000 \\
Constant & .664 & .372 & 1.783 & .076 \\
iHISB & -.051 & .039 & -1.311 & .192 \\
SHAI-14 & -.127 & .040 & -3.164 & .002 \\
CCLS & -.020 & .038 & -.512 & .610 \\
iHISB x CCLS & Effect & Boot S.E. & $\mathbf{9 5 \%}$ CI \\
\hline Conditional effects at moderator & .013 & .011 & {$[-.001, .048]$} \\
\hline SD below & .008 & .008 & {$[-.000, .034]$} \\
Mean & .007 & .010 & {$[-.006, .037]$} \\
1 SD above & & & & \\
\hline
\end{tabular}

Note. $\mathrm{N}=186$. All $\mathrm{p}$ values, two-tailed. $\mathrm{DV}=$ dependent variable; $\mathrm{CI}=$ confidence interval. Mediator model $\mathrm{R}^{2}=.023$; Outcome model $\mathrm{R}^{2}=.091$.

SWLS=The Satisfaction with Life Scale; SHAI-14=Health Anxiety Inventory-14 item; iHISB=Internet Health Information Seeking Behavior. All p values, two-tailed 


\section{CHAPTER V}

\section{DISCUSSION}

The purpose of this study was to explore associations among anxiety, health information seeking behavior, cross-cultural loss and satisfaction with life among East Asian international students; this may be the first study to examine such connections among this population. Results of this study provided support for the roles anxiety and Internet health information seeking behaviors might play among international students' satisfaction with life. It would be appeared that the higher an individual's health-related and overall anxiety, the lower their satisfaction with life might be. In addition, it provided additional support for the mediating role of health information seeking behavior in the relationship between health anxiety and satisfaction with life. In this section, a summary of the findings will be included and the results will be further discussed in the context of existing health and international student literature. Findings were organized according to the original four research questions. Contributions and limitations of the study as well as implications for research and practice will also be discussed.

\section{Findings from Preliminary Analyses}

Based on the preliminary results, nearly half of the East Asian international students in the sample have not had a doctor's visit during the past six months, while the other half reported having at least one time visit to their doctor's office. While it may not be sensible to directly generalized the findings related to doctor's visits to international students' health status, the findings provide additional insights regarding medical help seeking pattern among East Asian international students that were not available before. Possible topics to explore in the future to further this area of research is to potentially 
explore the medical decision-making process, such as how many of these international students who indicated no visits to the physicians might have chosen to have gone to seek medical treatment if they were back home or had not sought health related information online. It is also worth noting that within this sample, approximately five percent of the total participants indicated that they have gone to the doctors for either five to nine times, or ten times or more in the past six months. While we do not know the reasons for their doctor's visits and again cannot infer their health status simply based on these findings, the percentage of international students who reported at least several doctor's visits within the past year within the current study mimic the $5.3 \%$ of international students studying in Australia who reported having experienced significant interference on their studies as a result of having "poor" health (Rosenthal, Russell, \& Thomson, 2008).

Over eighty percent of the participants within this study reported that they have either searched illness $(12 \%, \mathrm{~N}=12)$, wellness $(16.7 \%, \mathrm{~N}=31)$ or both illness and wellness combine health related information online in the past 6 months. This provides further evidence that Internet is a widely used tool searching for health-related information among East Asian International students. As HISB can be divided into active (e.g. Internet, medical books, or helplines via telephone) versus passive (e.g. television and radio, paper and magazine, or social contact such as patients and friends) searches (Carlsson, 2000), there is a high probability that the Internet is not only used to "search for" and "research" health-related information, but it can be a medium to "passively" receive information without even having to search for it (e.g. feeds on Social Media or accidentally stumbling upon information when searching for something else). With such high percentage of international students already using the Internet for purposes of 
searching for health, this may have immense implications for university health education and promotion planning, particularly when it comes to providing education and information to international students regarding their health.

In terms of language preferences for health Information Seeking on the Internet, for those that disclosed language usage of their Internet information search, more than two-third of the participants $(66.1 \%, \mathrm{~N}=121)$ preferred to use their native language searching health related information online than English. With the results from the Chisquare test performed to test the association between English and native language usage while searching for health-related information through the Internet, there was a significant difference between language usage and Internet health-related Information Seeking $\left(X^{2}=4.66, \mathrm{df}=1, p<.05\right)$. Specifically, nearly $70 \%$ of international students who search health-related information (either illness or wellness) through the Internet would tend to use their native languages than English. As majority of participants in current study were graduate students, with their average length of stay being 4.7 years, it is interesting to find that they still appeared to have a preference for their native language when searching for health information online. While it may be impossible to have information readily available in all languages, translating crucial and important information in various languages might make the "messages" more user-friendly, decrease potential misunderstanding and increase international students' motivation to read it.

Based on the results, there does not appeared to be a "gender" effect in terms of the language preference $\left(X^{2}=.57, \mathrm{df}=2, p=.765\right)$ while using the Internet to search health-related information among East Asian international students; nor is there a 
relationship between gender and Internet Health Information Seeking Behavior $\left(X^{2}=1.60\right.$, $\mathrm{df}=2, p=.412$ ), meaning that there were no statistically meaningful differences in how men and women in this sample searched for information online. This lack of "gender" effect appeared to differ from findings in previous studies (Czaja et al, 2003) where they found that women tend to be more active information seekers compared to men. One possible factor that might have contributed to not having significant gender differences among East Asian international students might have been due to using the Internet as the "tool" for health information search and how men and women might approach information and help-seeking this way. Due to gender socialization, men might have been more reluctant to seek or ask for help due to socialization of masculinity growing up, including health information seeking, as compared to women. However, the Internet offers a rather private setting for men to ask information and serve as a "socially acceptable" forum to do so, thus there might not have been significant gender differences because of the medium used. Other factors such as the relative young age of the participants within the study, their education level and health literacy in particular might have also contributed to not having significant gender differences in terms of health information seeking.

\section{Connecting General and Health Anxiety with Well-being}

Exploring the relationship between anxiety and satisfaction with life in hypothesis 1, it was originally hypothesized there is a significant, negative relationship between anxiety (both general and health anxiety) and satisfaction with life (SWLS). Results provided support for the original hypothesis; as anxiety increases for East Asian international students during their stay in the U.S., whether it is general or health-specific 
anxiety, their overall satisfaction with life is likely to decline. Findings of current study appeared to be consistent with results found in past literature. Higher level of general anxiety has been associated with lower life satisfaction and quality of life among adolescents in U.S. (Derdikman-Eiron, Hjemdal, Lydersen, Bratberg, \& Indredavik, 2013) and lower general well-being among undergraduates in Europe (Kãteles \& Simor, 2014), while health-anxiety in particular was negatively correlated with satisfaction with life among nursing students in China (Zhang, Zhao, Mao, Li, \& Yuan, 2014).

Considering common acculturative challenges well-documented in the literature for many East Asian international students (e.g. Zhang \& Goodson, 2011), the inverse relationship between anxiety and satisfaction with life is concerning. International students' acculturation process has garnered much attention in the literature. In particular, Ward (2001) explored aspects of acculturation, including psychological adaptation and specifically what it means to "feel well", which he conceptualized broadly as a combination of lacking in psychological problems (such as anxiety) along with presence of well-being (such as satisfaction with life). Connecting concepts of successful adaptation and "feeling well" with results of current study, it might entail a "doublewhammy" that for those East Asian international students, who may particularly struggle psychologically during acculturation, as they experience higher anxiety and lower satisfaction with life. Given that international students may have different adjustment profile and trajectory over time, it would be useful for future research to further examine to see if this relationship changes at different time points of their studying abroad, as well as if it varies based on the types of profile they might have. For example, for international students who are "consistently distressed" (Wang et al, 2012, p 430) or 
"culturally shocked" (Wang et al, 2012, p 430) versus those who might belong to the overall "well-adjusted" (Wang et al, 2012, p 429), it is likely changes in anxiety level among these three groups of international students with distinct profile might impact their satisfaction with life differently.

Interestingly, as current study used two ways to measure health anxiety (e.g. SHAI-18 item and SHAI-14 item), only health anxiety measured by the 18 -item full version of SHAI (14-item health anxiety main subscale with 4-item aimed at measuring perceived negative consequences of becoming ill) was associated with satisfaction with life. Seeing as they are relatively young with average age of current participants being approximately 26-year-old, assuming majority of them experience little to no major health concerns or serious illness, it may be possible that only when health anxiety is combined with perceiving the possibilities of becoming seriously ill would they experience a decline in satisfaction with life, but not when they are simply experiencing general concerns or mild anxiety about health.

In a study examining health and well-being of international students studying abroad in Australia in which majority of participants are originally from East Asia (Rosenthal, Russell, \& Thomson, 2008), the results indicated that many students reported having "moderate" or "extremely severe" anxiety, more so than stress and depression. Despite having studied international students studying abroad in Australia, participants in that study appeared to be comparable to international students in the current study in many other aspects. Majority of the participants in the Australian study were 20 to 24 years old and over 70\% of them were post-graduate (Rosenthal, Russell, \& Thomson, 2008), compared to international students in the current study whose average age was 26 
and over $63 \%$ of them were pursuing a graduate-level degree. Given the results related to hypothesis 1 , it provides additional evidence of the links between anxiety and well-being for international students. More attention in future research on the relationships of anxiety and satisfaction with life, or overall well-being in general, among East Asian international students might shed light on their overall adjustment in the U.S.

\section{Searching Health Information on the Internet and its association with Anxiety}

With increasing use of Internet worldwide, it is not surprising that searching on the Internet for health related information is common among East Asian International Students. Considering that $83 \%$ of participants in the current sample indicated that they used Internet in the past week to search for 1) illness only, 2) wellness only, or 3) both illness and wellness related information, more exploration of Internet health information search behaviors among international students will be useful in the future.

In hypothesis 2 , it was hypothesized that there is a significant, positive relationship between anxiety and iHISB. As general anxiety was not found to be linked with Internet health information seeking behavior (iHISB) in this study, hypothesis 2 would be rejected, as there is no positive, significant relationship between general anxiety and Internet health information seeking behavior. Depending on how health anxiety is conceptualized, while overall health anxiety (SHAI-18) was not associated with Internet health information seeking behavior, if health anxiety is conceptualized by using the main 14-item subscale of the SHAI developed by Salkovskis and his colleagues (2002), as many previous studies have done (e.g. Lee, Fong, Piper, \& Feigon, 2014), there was support for a positive relationship between health anxiety and Internet health information seeking behavior. 
The inconsistent results related to the two ways "health anxiety" can be measured and how they each separately relate to the outcome appeared to echo controversies researchers such as Lee and colleagues (2014) have had related to what SHAI-18 and SHAI-14 aimed to capture in terms of health anxiety. One possible explanation for the differences in outcome is that an individual can be said to be anxious about their health even without perceiving how ill they might be, which is what the four additional items in SHAI-18 seemed to measure that SHAI-14 does not.

Simply using SHAI-14 as a reference point for health anxiety within this study, the findings suggest that for East Asian international students, the higher their health anxiety, they are more likely to engage in Internet health information seeking. Consistent with a previous study that sampled Dutch adults ages 18 to 30 , health anxiety appeared to be related to an increase in their use of searching the Internet for health information (Baumgartner \& Hartmann, 2011). Consistent with past research findings in the fields of medicine and psychology, health anxious individuals have been said to be more likely to seek more health-related information, and also more likely to seek medical consultation or utilize health care (Eastin \& Guinsler, 2006). However, this may not apply to East Asian international students. It has been noted that despite increases in their health anxiety and health seeking behavior, they may be unlikely to utilize health care due to cultural differences in medicine and unfamiliarity navigating the healthcare system, which can be concerning. Noting that within this study, general anxiety did not have significant relationship with Internet health information seeking. This may be because general anxiety captures a wide range of worries and fears that may be broad, not specific to and beyond health, thus there is no connection between general anxiety and health- 
specific behaviors, such as online health information seeking, to attempt to decrease the worries.

Other considerations to keep in mind when examining health anxiety and its relationship to health information searching behaviors online include how trustworthy individuals might deem the information they found as well as how they approach health anxiety management. For instance, it has been said that health anxious individuals experience more negative consequences from online health information search compared to non-health anxious individuals, but only if the information stems from a trustworthy governmental website (Baumgartner \& Hartmann, 2011). Using Theory of Motivation for Information Management (TMIM) as a guide, another explanation would be there are differences in how individuals approach coping with health anxiety, as some might find it more helpful to avoid information versus actively seeking them.

\section{Mediating Role of Health Information Seeking Behavior}

With number of studies focusing on health information seeking increasing steadily and garnering more attention (Anker et al., 2011), most studies have focused on actionrelated outcomes such as self-diagnosis, treatment seeking and decisions, very little emphasis has been placed on the connection between health information seeking behavior and psychological outcome. This study contributes to the literature by examining the mediating role of Internet health information seeking behavior in the relationship between anxiety and satisfaction with life for East Asian international students. It was originally hypothesized that Internet Health Information Seeking Behavior will mediate the relationship between anxiety and satisfaction with life, which was supported. International students' satisfaction with life, in response to their health anxiety, was 
mediated through Internet health information seeking behavior. In other words, the results indicated that higher levels of health anxiety are associated with higher levels of Internet health information seeking, which in turn are associated with lower levels of satisfaction with life.

As health anxiety appeared to lead international students to search for health information online, and as a result, their satisfaction with life consequently decreases. One implication of this result is that finding ways to help international students sort through what it is they are anxious about health-wise and determining how to effectively manage that anxiety might be helpful, particularly considering how damaging this anxiety might be to their psychological well-being. As Eastin and Guinsler (2006) suggested, even for individuals with moderate level of anxiety seek information online, and frequent information seekers also tend to make medical appointments. Taking it a step further, it would be useful to see if this applied for international students and consequent actions they might take regarding their health after seeking information, particularly considering most international students only seek medical attention from physicians or health professionals as a last resort (Collins, 2001).

The process of decision-making related to health may be an area to explore further, particularly with international students. While beyond the scope of the current study, another possible area to further explore is the connection between health anxiety, health information seeking and consequent health-related decisions and actions. Anxiety may not be a bad thing if it is appropriate to worry. It is worth exploring how do international students decide what to do after obtaining or receiving health related information, particularly related to illness? For instance, for individuals with lower 
anxiety, there was a negative relationship between finding information online and seeking doctor (Weaver et al., 2010), which implied that their level of anxiety could lead them to "determine" or at least make a decision that there is nothing to worry about, regardless whether that decision is "right" medically speaking or not. Thus, further exploring international students' level of health literacy and self-efficacy in making decisions might be a topic worth investigating more. The questions worth exploring may include what types of actions do they typically take after seeking information, and if they are able to take reasonable actions, whether it is to seek help or find ways to alleviate worry since there is actually nothing to be worried about.

Beyond the scope of this study, another question worth digging further would the types of information being sought make a difference in the existing mediation model? For instance, would health anxious individuals who only search for wellness related information actually have higher satisfaction with life? This would fit previous findings where wellness information seekers were associated with positive health indicators and lowest health risk, while the opposite is true for their illness information-seeking counterparts (Weaver et al., 2010).

\section{Loss during Cross Cultural Transition}

Experiences of loss during cross-cultural transition have been linked with low satisfaction with life and positive affect for international students (Wang et al., 2015). Thus, further exploring the role of cross-cultural loss and particularly in the relationship between health information seeking behavior and satisfaction with life appear to be sensible, as international students attempt to navigate loss of national privilege, access to resources and familiarity of home country, as well as establishing their belongingness and 
competency in their new environment. Aimed to test the moderated-mediation in hypothesis 4 , it was originally assumed that cross-cultural loss (CCLS) would moderate the relationship between Internet health information seeking behavior (iHISB) and satisfaction with life (SWLS). Specifically, with CCLS as a moderator, it might strengthen the association between iHISB and SWLS; for international students who experience greater sense of loss, the more health information they seek and obtain, the lower their satisfaction with life will be. However, the hypothesis was rejected.

When examined the moderating effects of loss, results of this study suggest that experiencing higher levels of cross-national loss does not change the relationship between Internet Health Information Seeking Behavior and satisfaction, as compared to those who endure low levels of loss. One possible explanation is that as sense of loss may change over time or be accumulative (Wang et al., 2015), since current study employs a cross-sectional design, it may be harder to capture international students' perception of loss over time. With increased recommendation to examine international students' acculturative experiences over time, future studies using a longitudinal research design examining the moderating effects cross different time points, such as prior to coming to the U.S. in their home country, as they begin cross-cultural transition, and after initial period of acculturation, it might provide a different angle on the topic.

Within this study, despite the strong associations cross-cultural loss has with the predictor (general and health anxiety) and outcome variable (satisfaction with life), it was not related to the mediator, Internet health information seeking. In other words, changes in cross-cultural loss do not appeared to be linked in changes in Internet health information. As the average length of stay in the U.S. is nearly five years in the current 
sample, it might be worth further examining if this relationship might be different among East Asian international students at their initial stages of arrival, either during the first few months of their arrival or a semester after, where their cross-cultural loss might be more significant. As time passes, most international students are also more likely to have adjusted or found a way to cope with these losses. Particularly related to health-related concerns, it might be interesting to explore how international students' coping strategies might change the relationship between cross-cultural or national losses and health information seeking behaviors online.

\section{Limitations and Future Directions}

Limitations to current study as well as future research possibilities should be noted. First, recruitment of the study participants primarily involved using a snowball sampling approach via social media (e.g. Facebook), international student campus organization webpages or listserv, there may be selection bias of who had access to recruitment information or who decided to participate.

In this study, students from the following four countries (e.g. China, Japan, Korean, and Taiwan) were lumped together as East Asian international students. Despite commonalities and similarities among East Asian international students, individual and subtle within group cultural differences must be taken into consideration when blindly generalizing findings of this study to all East Asian international students. For instance, findings from a study investigating health beliefs among Indian-born and Chinese-born international students reflects that students from these two countries varied significantly in their beliefs due to religious differences and the confidence they put on friends and family to help them to recover from illnesses (Rothstein and Rajapaksa, 2003). Subtle 
and yet important cultural differences such as these provide additional guidelines for student health services on college campuses to exercise more cultural sensitivity when interacting with this population. Thus, it is important to recognize applicability of research findings from this study, while also challenging common stereotypes that all international students from East Asia must share similar beliefs related to health.

Future studies may benefit from examining these groups of students separately based on country of origin as well as recruit international students from other countries to see if differences exist. It may also be interesting to sample international students studying in the U.S. and general "American" college students to see how they might differ in terms of these outcomes.

Next, as this study employed a quantitative design, conducting both qualitative and mixed method studies might provide a different perspective on the subject (e.g. conducting interviews or "fill-in" text to explore international students' Internet health information search and how this might have changed as a result of coming to study in the U.S.). In addition, as health related issues can often be multi-faceted, it would be interesting to design a longitudinal study that track changes in international students' understanding of the U.S. healthcare system, insurance and cultural-specific approaches to health and if this knowledge changes their Health Information Seeking Behavior over time. A multiple-time points longitudinal design might also be desirable to capture changes in cross-cultural loss.

The construct on Internet health information seeking behavior needs further exploring, particularly with international students. Exploring if their method and intentionality for searching information online has changed since crossing national 
boundaries from their country of origin to the U.S. might be a possible next step to pursue, as well as whether or not those changes influences their health anxiety or decisionmaking behavior related to health. While it was beyond the scope of current study, exploring international students' health information literacy might be warranted, as it is likely that their knowledge about health and healthcare system might impact their anxiety or how they search for information.

As in a previous study, the act of seeking health information appeared to result in greater worry among already health anxious individual, but only if the information is derived from trustworthy governmental website (Baumgartner \& Hartmann, 2011), it might be worth replicating this study among international students to see if moderating role of trustworthiness changes relationship between health information and satisfaction with life.

\section{Practical Implications}

As it is important to create and improve culturally tailored services for international students, there are several implications related to international students and their health and well-being while studying abroad in the U.S. Findings of this current study provide practical guidelines on universities across the U.S. can better serve East Asian international students in terms of health management and information seeking. As general and health-related anxiety appeared to be related to international students' overall satisfaction with life, to help facilitate better cross-cultural transition and adjustment, providing concrete and practical solutions or tips on how to manage anxiety in general and health anxiety would be helpful in improving their overall well-being. If staff members at the International Center and Student Health Center who might interact with 
international students were aware of how general and health anxiety impact international students' well-being, they might be able to collaborate on finding ways to disseminate useful preventative and intervening psychoeducational information to students. For instance, many International Centers have hard copies of brochures related to various aspects of adjustment and life in the U.S. at their offices, or have similar information on their website, on topics such as how to apply for a driver's license or how to set up bank accounts. Including information to talk about how to navigate the healthcare system in the U.S., links to major, credible health-related websites, as well as how to recognize and manage anxiety might be useful. Since many of these international students appeared to be familiar with searching information online, they might consider posting or sharing it on their website, listserv, social media sites or working with various student organizations on campus to disseminate information. For students with more severe symptoms of anxiety, it might to helpful to encourage international students to further explore their general and health related issues with healthcare providers such as physicians or therapists.

As health anxiety is related to health information seeking for East Asian international students, helping them further determine how their health information seeking behaviors may actually help to ease or rise their health anxiety would be helpful. Depending on their level of anxiousness, for some individuals, being concerned about something and then proactively search for information might feel empowering as they are taking control of a situation; versus for others, while having too much information might feel overwhelming and not actually conducive to managing their anxiety. Thus, it would be helpful to provide psychoeducation on different strategies to manage anxiety and 
encourage these international students to find the most fitting way for them to move forward.

\section{Conclusion}

Up until recently, only a few studies existed to examine health anxiety and health information seeking behavior, but none of them focused on international students' unique experiences while studying abroad. To my best knowledge, this is the first study to date to explore connection between general anxiety, health anxiety, health information seeking behavior, and satisfaction with life for international students. With hopes that this study will strengthen the understanding of international students' health anxiety and Internet health information seeking behavior for higher education scholars and researchers, more studies on related topics are warranted to further advance this research area. The results of this study provide additional knowledge about East Asian international students' health, including the connection between general and health anxiety, Internet health information seeking behavior, and satisfaction with life. Findings from this study may have implications for higher education institutions serving international students. 


\section{References}

Afifi, W. A., \& Weiner, J. L. (2004). Toward a theory of motivated information management. Communication Theory, 14(2), 167-190.

Alberts, N. M., Hadjistavropoulos, H. D., Jones, S. L., \& Sharpe, D. (2013). The Short Health Anxiety Inventory: A systematic review and meta-analysis. Journal of Anxiety Disorders, 27(1), 68-78.

American College Health Association. (2008). American College Health AssociationNational College Health Assessment spring 2007 reference group data report (abridged). Journal of American college health, 56(5), 477-488. doi:10.3200/JACH.57.5.477-488

American Psychological Association. (n.d.). Anxiety. Retrieved from http://www.apa.org/topics/anxiety/

Anker, A. E., Reinhart, A. M., \& Feeley, T. H. (2011). Health information seeking: a review of measures and methods. Patient education and counseling, 82(3), 346354.

Arredondo-Dowd, P. M. (1981). Personal loss and grief as a result of immigration. Personnel \& Guidance Journal, 59, 376 -378. doi:10.1002/j.21644918.1981.tb00573.x

Atkinson, N., Saperstein, S., \& Pleis, J. (2009). Using the Internet for health-related activities: Findings from a national probability sample. Journal of medical Internet research, 11(1), e5.

Austin, S. T. (2013). International and Domestic Student Health-Information Seeking and Satisfaction. Unpublished manuscript, Department of Communications, Portland 
State University, Oregon, United States.

Baron, R. M., \& Kenny, D. A. (1986). The moderator-mediator variable distinction in social psychological research: Conceptual, strategic, and statistical considerations. Journal of personality and social psychology, 51(6), 1173.

Baumgartner, S. E., \& Hartmann, T. (2011). The role of health anxiety in online health information search. Cyberpsychology, behavior, and social networking, 14(10), 613-618.

Bowen, D. J., Ludman, E., Press, N., Vu, T., \& Burke, W. (2003). Achieving utility with family history: colorectal cancer risk. American journal of preventive medicine, 24(2), 177-182.

Brashers, D. E. (2001). Communication and uncertainty management. Journal of communication, 51(3), 477-497.

Carlsson, M. E. (2000). Cancer patients seeking information from sources outside the health care system. Supportive care in cancer, 8(6), 453-457.

Carmack, H. J., Bedi, S., \& Heiss, S. N. (2015). International students, university health centers, and memorable messages about health. Journal of International Students, $6(1), 52-72$.

Carr, J.L., Koyama, M., \& Thiagarajan, M. (2003). A women's support group for Asian international students. Journal of American College, 52(3), 131-134.

Casado, B. L., \& Leung, P. (2002). Migratory grief and depression among elderly Chinese American immigrants. Journal of Gerontological Social Work, 36(1-2), $5-26$.

Chan, Y.M. (2015). The Confidence of Health Information Seeking Behaviors from the 
Internet. Academic Research International, 6(1), 104-114.

Chen, Y. W. (2006). Intercultural friendship from the perspective of East Asian international students. China Media Research, 2(3), 43-58.

Chen, H. J., Mallinckrodt, B., \& Mobley, M. (2002). Attachment patterns of East Asian international students and sources of perceived social support as moderators of the impact of US racism and cultural distress. Asian Journal of Counselling, 9(1-2), $27-48$.

Cheng, H. I. C. (2005). Being ill in a foreign land: international students' perceptions of and experiences with university health services. Submission INFORMATION Submission period for Fall 2005 issue: January 1-May 15, 2005, 70.

Cheong, P. H. (2007). Health communication resources for uninsured and insured Hispanics. Health Communication, 21(2), 153-163.

Collins, K. F. (2001). International students' perceptions of health care. The Journal of School Nursing, 17(3), 140-147.

Czaja, R., Manfredi, C., \& Price, J. (2003). The determinants and consequences of information seeking among cancer patients. Journal of health communication, $8(6), 529-562$.

Department of Further Education, Employment, Science, \& Technology, Multicultural SA and the Department for Health and Ageing. (2013). International Student Health and Wellbeing: A Health Lens Project (Rep.).

Derdikman-Eiron, R., Hjemdal, O., Lydersen, S., Bratberg, G. H., \& Indredavik, M. S. (2013). Adolescent predictors and associates of psychosocial functioning in young men and women: 11 year follow-up findings from the Nord-Trøndelag Health 
Study. Scandinavian journal of psychology, 54(2), 95-101.

Deumert, A., Marginson, S., Nyland, C., Ramia, G., \& Sawir, E., (2005). Global Migration and Social Protection Rights: The Social and Economic Security of Cross-Border Students in Australia, Global Social Policy, 5(3): 329-352.

Diener, E., Emmons, R., Larsen, R., \& Griffin, S. (1985). The Satisfaction with Life Scale. Journal of Personality Assessment, 49, 71-75. doi: 10.1207/s15327752jpa4901_13

Eastin, M. S., \& Guinsler, N. M. (2006). Worried and wired: Effects of health anxiety on information-seeking and health care utilization behaviors. Cyber Psychology and Behavior, 9, 494-498. doi:10.1089/cpb.2006.9.494

Ellis-Bosold, C., \& Thornton-Orr, D. (2013). A needs assessment: A study of perceived need for student health services by Chinese international students. College Student Journal, 47(1), 155-168.

Eysenbach, G., Powell, J., Kuss, O., \& Sa, E. R. (2002). Empirical studies assessing the quality of health information for consumers on the World Wide Web: a systematic review. Jama, 287, 2691-2700.

Fox, S. (2006). Online Health Search 2006. Retrieved from http://www.pewInternet.org/2006/10/29/part-2-a-typical-search-for-healthinformation/

Fox, S. (2008). Pew Research Center's Internet \& American Life Project: The Engaged E-patient Population. Retrieved from http://www.pewInternet.org/files/oldmedia//Files/Reports/2008/PIP_Health_Aug08.pdf.pdf

Fox, S., \& Duggan, M. (2013). Pew Research Center's Internet \& American Life Project: 
Health Online 2013. Retrieved from www.pewInternet.org/files/oldmedia/Files/Reports/PIP_HealthOnline.pdf

Frey, L. L., \& Roysircar, G. (2006). South Asian and East Asian international students' perceived prejudice, acculturation, and frequency of help resource utilization. Journal of Multicultural Counseling and Development, 34(4), 208.

Grace, T. (1997). Health problems of college students. Journal of American College Health, 45, 243-250

Hashimoto, H., \& Fukuhara, S. (2004). The influence of locus of control on preferences for information and decision making. Patient education and counseling, 55(2), 236-240.

Hayes, A. F. (2009). Beyond Baron and Kenny: Statistical mediation analysis in the new millennium. Communication monographs, 76(4), 408-420.

Hayes, A. F. (2013). Introduction to mediation, moderation, and conditional process analysis: A regression-based approach. New York: The Guilford Press.

Hemsel, G., Leshner, R., \& Logan, R. (2010). CHIRr: Consumer Health Informatics Research resource: Health Information Seeking. Retrieved from http://chirr.nlm.nih.gov/health-information-seeking.php

Institute of International Education. (2015). “Open Doors Report on International Educational Exchange." Retrieved from http://www.iie.org/opendoors" Institute of International Education. (2016). “Open Doors Data.” Retrieved from http://www.iie.org/Research-and-Publications/Open-Doors/Data/International$\underline{\text { Students\#.WMrbR8J1qoB }}$ 
Johnson, L. R., \& Sandhu, D. S. (2007). Isolation, adjustment, and acculturation issues of international students: Intervention strategies for counselors. A handbook for counseling international students in the United States, 13-35.

Kãteles, F., \& Simor, P. (2014). Modern Health Worries, Somatosensory Amplification, Health Anxiety, And Well-Being. European Journal Of Mental Health, 9(1), 2033.

Kaul, A. (2001). Predictors of positive adaptation among international students in the United States. Unpublished doctoral dissertation. University of Memphis.

Kenny, D. A., Kashy, D. A., \& Bolger, N. (1998). Data analysis in social psychology. In D. Gilbert, S. Fiske, \& G. Lindzey (Eds.). The handbook of social psychology ( $^{\text {th }}$ ed., Vol. 1, pp. 233-265). New York: McGraw-Hill.

Kim, B. S., Atkinson, D. R.,\& Yang, P. H. (1999). The Asian Values Scale: Development, factor analysis, validation, and reliability.Journal of Counseling Psychology, $46(3), 342$.

Lambert, S. D., \& Loiselle, C. G. (2007). Health information - seeking behavior. Qualitative health research, 17(8), 1006-1019.

Lee, E. J., Ditchman, N., Fong, M. W., Piper, L., \& Feigon, M. (2014). Mental health service seeking among Korean international students in the United States: A path analysis. Journal of Community Psychology, 42(6), 639-655.

Li, P., Wong, Y. J., Toth, P. (2013). Asian international students willingness to seek counseling: A mixed-methods study. International Journal for the Advancement of Counselling, 35, 1-15. doi: 10.1007/s10447-012-9163-7

Loiselle, C. G., Lambert, S. D., \& Cooke, A. (2006). The searching, processing, and 
sharing of breast cancer information by women diagnosed with the illness.

Canadian Journal of Nursing Research, 38 (3), 82-104.

Lovibond, P. F., \& Lovibond, S. H. (1995). The structure of negative emotional states:

Comparison of the Depression Anxiety Stress Scales (DASS) with the Beck Depression and Anxiety Inventories. Behaviour research and therapy, 33(3), 335343.

Lucock, M. P., \& Morley, S. (1996). The health anxiety questionnaire. British Journal of Health Psychology, 1(2), 137-150.

Miniwatts Marketing Group. (2015). Internet Usage in Asia. Retrieved from http://www.Internetworldstats.com/stats3.htm

Mitchell, S. L., Greenwood, A. K., \& Guglielmi, M. C. (2007). Utilization of counseling services: Comparing international and US college students. Journal of College Counseling, 10(2), 117-129.

Miyazaki, Y., Bodenhorn, N., Zalaquett, C., \& Ng, K. M. (2008). Factorial structure of Brief COPE for international students attending U.S. colleges. College Student Journal, 42, 795-806.

Miville, M. L., \& Constantine, M. G. (2007). Cultural values, counseling stigma, and intentions to seek counseling among Asian American college women. Counseling and Values, 52(1), 2.

Myers-Walls, J. A., Frias, L. V., Kwon, K. A., Ko, M. J., \& Lu, T. (2011). Living Life in Two Worlds: Acculturative Stress among Asian International Graduate Student Parents and Spouses. Journal of Comparative Family Studies, 42(4), 455-478 
Nelson, D., Kreps, G., Hesse, B., Croyle, R., Willis, G., Arora, N., Rimer, B., Viswanath, k.V., Weinstein, N. \& Alden, S. (2004). The health information national trends survey (HINTS): Development, design, and dissemination. Journal of health communication, 9(5), 443-460. DOI: 10.1080/10810730490504233

Nelson, D., Kreps, G., Hesse, B., Croyle, R., Willis, G., Arora, N., Rimer, B., Viswanath, K.V., Weinstein, N. \& Alden, S. (2004). The health information national trends survey (HINTS): Development, design, and dissemination. Journal of health communication, 9(5), 443-460. DOI: 10.1080/10810730490504233

Nilsson, J. E., \& Anderson, M. Z. (2004). Supervising International Students: The Role of Acculturation, Role Ambiguity, and Multicultural Discussions. Professional Psychology: Research and Practice, 35(3), 306. DOI: /10.1037/07357028.35.3.306

Niederdeppe, J., Hornik, R. C., Kelly, B. J., Frosch, D. L., Romantan, A., Stevens, R. S., \& Schwartz, J. S. (2007). Examining the dimensions of cancer-related information seeking and scanning behavior. Health communication, 22(2), 153-167.

Norton, P. J. (2007). Depression Anxiety and Stress Scales (DASS-21): Psychometric analysis across four racial groups. Anxiety, stress, and coping, 20(3), 253-265.

Perko, M. A., Woodhouse, L., Jones, C. S., \& Green, B. L. (1996). Using focus groups to assess international students' perceptions about substance use and related services available to them at an American university. Journal of Health Education, 27, 130-131.

Perrin, A., \& Duggan, M. (2015). Americans' Internet access: 2000-2015. Pew Research Center, 26. Retrieved from http://www.pewInternet.org/2015/06/26/americans- 
Internet-access-2000-2015/

Pew Research Center. (2012). Health Fact Sheet. Retrieved from http://www.pewInternet.org/fact-sheets/health-fact-sheet/

Positive Psychology Program. (2015). Life-satisfaction and Its 7 Contributors. Retrieved from https://positivepsychologyprogram.com/life-satisfaction/

Preacher, K. J., \& Hayes, A. F. (2008). Asymptotic and resampling strategies for assessing and comparing indirect effects in multiple mediator models. Behavior research methods, 40(3), 879-891.

Prescott, H. (2011). Student bodies, past and present. Journal of American College Health, 59(6), 464-469.

Rakhsha, G. (2002). Crossing global boundaries: Experiences of loss by international students. Network of Multicultural Training Professionals Newsletter, 6(1).

Rew, L. (1997). Ethnic differences in adolescents' perceived health status: Preliminary findings. Journal of pediatric nursing, 12(4), 223-227.

Rosenthal, D. A., Russell, J., \& Thomson, G. D. (2006). A growing experience: The health \& well-being of international students at the University of Melbourne. University of Melbourne.

Rosenthal, D. A., Russell, J., \& Thomson, G. (2008). The health and wellbeing of international students at an Australian university. Higher Education, 55(1), 51-67. DOI 10.1007/s10734-006-9037-1

Rothstein, W.G. \& Rajapaksa, S. (2003) Health Beliefs of College Students Born in the United States, China, and India, Journal of American College Health, 51(5), 189194. DOI: $10.1080 / 07448480309596350$ 
Sadler, C. (2005). Campus care. Nursing Standards, 20(6), 22-23.

Salkovskis, P. M., Rimes, K. A., Warwick, H. M. C., \& Clark, D. M. (2002). The Health Anxiety Inventory: development and validation of scales for the measurement of health anxiety and hypochondriasis. Psychological medicine,32(5), 843-853.

Sam, D. L. (2001). Satisfaction with life among international students: An exploratory study. Social indicators research, 53(3), 315-337.

Sobel, M. E. (1982). Asymptotic confidence intervals for indirect effects in structural equation models. Sociological methodology, 13, 290-312.

Sørensen, T. (2008). WHO/European eHealth consumer trends survey. Final project report. Health \& Consumer Protection Directorate General-Health Information.

Souto-Otero, M., Huisman, J., Beerkens, M., de Wit, H. and Vujić, S. (2013). Barriers to International Student Mobility: Evidence from the Erasmus Program'. Educational Researcher, 42(2), 70-77.

Stark-Wroblewski, K., Yanico, B. J., \& Lupe, S. (2005). Acculturation, internalization of Western appearance norms, and eating pathology among Japanese and Chinese international student women. Psychology of Women Quarterly, 29(1), 38-46.

Tian Y, \& Robinson J.D. (2009). Incidental health information use on the Internet. Health Communication, 24(1), 41-49.

Thomson, G., Rosenthal, D., \& Russell, J. (2006). Cultural stress among international students at an Australian university. Paper presented at Australian international education conference. Retrieved from www.idp.com/aiec

United States of the Department of Health and Human Services. (2006). Estimating the Proportion of Health-Related Websites Disclosing Information That Can Be Used 
to Assess Their Quality (Rep.).

Wang, K. T., Heppner, P. P., Fu, C.-C., Zhao, R., Li, F., \& Chuang, C.-C. (2012). Profiles of acculturative adjustment patterns among Chinese international students. Journal of Counseling Psychology, 59(3), 424-436. doi: $10.1037 / \mathrm{a} 0028532$

Wang, K. T., Wei, M., Zhao, R., Chuang, C., \& Li, F. (2015). The Cross-Cultural Loss Scale: Development and Psychometric Evaluation. Psychological assessment, 27(1), 42-53. doi:10.1037/pas0000027

Ward, C. (2001). The A, B, Cs of acculturation. The handbook of culture and psychology, 411-445.

Weaver III, J. B., Mays, D., Weaver, S. S., Hopkins, G. L., Eroğlu, D., \& Bernhardt, J. M. (2010). Health information-seeking behaviors, health indicators, and health risks. American journal of public health, 100(8), 1520-1525.

Wei, M. H. (2014). The associations between health literacy, reasons for seeking health information, and information sources utilized by Taiwanese adults. Health Education Journal, 73(4), 423-434.

Wei, M., Wang, K. T., \& Ku, T. (2012). A development and validation of the Perceived Language Discrimination Scale. Cultural Diversity and Ethnic Minority Psychology, 18, 340-351. doi: 10.1037/t01069-000

White, R. W., \& Horvitz, E. (2009). Cyberchondria: studies of the escalation of medical concerns in web search. ACM Transactions on Information Systems (TOIS), 27(4), 23.

Ye, J. (2005). Acculturative stress and use of the Internet among East Asian international 
students in the United States. CyberPsychology \& Behavior, 8(2), 154-161.

Ye, J. (2006). An examination of acculturative stress, interpersonal social support, and use of online ethnic social groups among Chinese international students. The Howard Journal of Communications, 17(1), 1-20.

Ye, Y. (2014). The role of illness factors and patient satisfaction in using online health support groups. Health Communication, 29(4), 355-363.

Yeh, C. J., \& Inose, M. (2003). International students' reported English fluency, social support satisfaction, and social connectedness as predictors of acculturative stress. Counselling Psychology Quarterly, 16(1), 15-28.

Zane, N., \& Mak, W. (2003). Major approaches to the measurement of acculturation among ethnic minority populations: A content analysis and an alternative empirical strategy.

Zhang, J., \& Goodson, P. (2011). Predictors of international students' psychosocial adjustment to life in the United States: A systematic review. International Journal of Intercultural Relations, 35(2), 139-162. doi:10.1016/j.ijintrel.2010.11.011

Zhang, Y., Zhao, Y., Mao, S., Li, G., \& Yuan, Y. (2014). Investigation of health anxiety and its related factors in nursing students. Neuropsychiatric disease and treatment, $10,1223-10234$ 


\section{Appendix A}

The short-form of Depression, Anxiety Stress Scale (DASS-21)

Directions: Please read each statement and circle a number $0,1,2$ or 3 which indicates how much the statement applied to you over the past week.

There are no right or wrong answers. Do not spend too much time on any statement.

The rating scale is as follows:

$0=$ Did not apply to me at all: NEVER

$1=$ Applied to me to some degree, or some of the time: SOMETIMES

$2=$ Applied to me to a considerable degree, or a good part of time: OFTEN

3 = Applied to me very much, or most of the time: ALMOST ALWAYS

*Items will be listed on the next page. 


\begin{tabular}{|c|c|c|c|c|c|}
\hline 1 & I found it hard to wind down & 0 & 1 & 2 & 3 \\
\hline 2 & I was aware of dryness of my mouth & 0 & 1 & 2 & 3 \\
\hline 3 & I couldn't seem to experience any positive feeling at all & 0 & 1 & 2 & 3 \\
\hline 4 & $\begin{array}{l}\text { I experienced breathing difficulty (e.g., excessively rapid } \\
\text { breathing, breathlessness in the absence of physical exertion) }\end{array}$ & 0 & 1 & 2 & 3 \\
\hline 5 & I found it difficult to work up the initiative to do things & 0 & 1 & 2 & 3 \\
\hline 6 & I tended to over-react to situations & 0 & 1 & 2 & 3 \\
\hline 7 & I experienced trembling (e.g., in the hands) & 0 & 1 & 2 & 3 \\
\hline 8 & I felt that I was using a lot of nervous energy & 0 & 1 & 2 & 3 \\
\hline 9 & $\begin{array}{l}\text { I was worried about situations in which I might panic and make } \\
\text { a fool of myself }\end{array}$ & 0 & 1 & 2 & 3 \\
\hline 10 & I felt that I had nothing to look forward to & 0 & 1 & 2 & 3 \\
\hline 11 & I found myself getting agitated & 0 & 1 & 2 & 3 \\
\hline 12 & I found it difficult to relax & 0 & 1 & 2 & 3 \\
\hline 13 & I felt down-hearted and blue & 0 & 1 & 2 & 3 \\
\hline 14 & $\begin{array}{l}\text { I was intolerant of anything that kept me from getting on with } \\
\text { what I was doing }\end{array}$ & 0 & 1 & 2 & 3 \\
\hline 15 & I felt I was close to panic & 0 & 1 & 2 & 3 \\
\hline 16 & I was unable to become enthusiastic about anything & 0 & 1 & 2 & 3 \\
\hline 17 & I felt I wasn't worth much as a person & 0 & 1 & 2 & 3 \\
\hline 18 & I felt that I was rather touchy & 0 & 1 & 2 & 3 \\
\hline 19 & $\begin{array}{l}\text { I was aware of the action of my heart in the absence of physical } \\
\text { exertion (e.g., sense of heart rate increase, heart missing a beat) }\end{array}$ & 0 & 1 & 2 & 3 \\
\hline 20 & I felt scared without any good reason & 0 & 1 & 2 & 3 \\
\hline 21 & I felt that life was meaningless & 0 & 1 & 2 & 3 \\
\hline
\end{tabular}




\section{Appendix B}

\section{Health Anxiety Inventory (SHAI-18)}

\section{Instructions:}

Each question consists of a group of four statements. Please read each group of statements carefully and then select the one which best describes your feelings over the past 6 months.

There are no right or wrong answers. Do not spend too much time on any one statement.

1. a.) I do not worry about my health.

b.) I occasionally worry about my health.

c.) I spend much of my time worrying about my health.

d.) I spend most of my time worrying about my health.

2. a.) I notice aches/pains less than most other people (of my age).

b.) I notice aches/pains as much as most other people (of my age).

c.) I notice aches/pains more than most other people (of my age).

d.) I am aware of aches/pains in my body all the time.

3. a.) as a rule I am not aware of bodily sensations or changes.

b.) sometimes I am aware of bodily sensations or changes.

c.) I am often aware of bodily sensations or changes.

d.) I am constantly aware of bodily sensations or changes.

4. a.) resisting thoughts of illness is never a problem.

b.) most of the time I can resist thoughts of illness.

c.) I try to resist thoughts of illness but am often unable to do so.

d.) thoughts of illness are so strong that I no longer even try to resist them.

5. a.) as a rule I am not afraid that I have a serious illness.

b.) I am sometimes afraid that I have a serious illness.

c.) I am often afraid that I have a serious illness.

d.) I am always afraid that I have a serious illness.

6. a.) I do not have images (mental pictures) of myself being ill.

b.) I occasionally have images of myself being ill.

c.) I frequently have images of myself being ill.

d.) I constantly have images of myself being ill.

7. a.) I do not have any difficulty taking my mind off thoughts about my health.

b.) I sometimes have difficulty taking my mind off thoughts about my health.

c.) I often have difficulty in taking my mind off thoughts about my health.

d.) Nothing can take my mind off thoughts about my health. 
8. a.) I am lastingly relieved if my doctor tells me there is nothing wrong.

b.) I am initially relieved but the worries sometimes return later.

c.) I am initially relieved but the worries always return later.

d.) I am not relieved if my doctor tells me there is nothing wrong.

9. a.) if I hear about an illness I never think I have it myself.

b.) if I hear about an illness I sometimes think I have it myself.

c.) if I hear about an illness I often think I have it myself.

d.) if I hear about an illness I always think I have it myself.

10. a.) if I have a bodily sensation or change I rarely wonder what it means.

b.) if I have a bodily sensation or change I often wonder what it means.

c.) if I have a bodily sensation or change I always wonder what it means.

d.) if I have a bodily sensation or change I must know what it means.

11. a.) I usually feel at very low risk for developing a serious illness.

b.) I usually feel at fairly low risk for developing a serious illness.

c.) I usually feel at moderate risk for developing a serious illness.

d.) I usually feel at high risk for developing a serious illness.

12. a.) I never think I have a serious illness.

b.) I sometimes think I have a serious illness.

c.) I often think I have a serious illness.

d.) I usually think that I am seriously ill.

13. a.) if I notice an unexplained bodily sensation I don't find it difficult to think about other things.

b.) if I notice an unexplained bodily sensation I sometimes find it difficult to think about other things.

c.) if I notice an unexplained bodily sensation I often find it difficult to think about other things.

d.) if I notice an unexplained bodily sensation I always find it difficult to think about other things.

14. a.) my family/friends would say I do not worry enough about my health.

b.) my family/friends would say I have a normal attitude to my health.

c.) my family/friends would say I worry too much about my health.

d.) my family/friends would say I am a hypochondriac. 
For the following questions, please think about what it might be like if you had a serious illness of a type which particularly concerns you (e.g. heart disease, cancer, multiple sclerosis \& so on). Obviously you cannot know for definite what it would be like; please give your best estimate of what you think might happen, basing your estimate on what you know about yourself and serious illness in general.

15. a.) if I had a serious illness I would still be able to enjoy things in my life quite a lot.

b.) if I had a serious illness I would still be able to enjoy things in my life a little.

c.) if I had a serious illness I would be almost completely unable to enjoy things in my life.

d.) if I had a serious illness I would be completely unable to enjoy life at all.

16. a.) if I developed a serious illness there is a good chance that modern medicine would be able to cure me.

b.) if I developed a serious illness there is a moderate chance that modern medicine would be able to cure me.

c.) if I developed a serious illness there is a very small chance that modern medicine would be able to cure me.

d.) if I developed a serious illness there is no chance that modern medicine would be able to cure me.

17. a.) a serious illness would ruin some aspects of my life.

b.) a serious illness would ruin many aspects of my life.

c.) a serious illness would ruin almost every aspect of my life.

d.) a serious illness would ruin every aspect of my life.

18. a.) if I had a serious illness I would not feel that I had lost my dignity.

b.) if I had a serious illness I would feel that I had lost a little of my dignity.

c.) if I had a serious illness I would feel that I had lost quite a lot of my dignity.

d.) if I had a serious illness I would feel that I had totally lost my dignity. 


\section{Appendix C}

Internet Health Information Seeking Behavior (iHISB)

1. During a typical week, about how many hours do you spend on the Internet obtaining information for

\section{Hour(s) Minute(s)}

\begin{tabular}{l} 
Treatment \\
\hline Medication \\
\hline Parenting \\
\hline
\end{tabular}

Nutrition or Diet

Exercise/ Physical Activities

Illness/Disease

Medical Insurance benefits

2. Is there a specific website you like to go to for health or medical information?

If the answer is yes, please indicate

3. During a typical week, about how many hours do you spend on the Internet for the following activities:

\section{Hour(s) Minute(s)}

\section{Work/Study related search}

Social Networking (Facebook, twitter, and others)

\section{Games}

Others 


\section{Directions:}

Please read each statement carefully and choose one of the numbers from $0,1,2,3$ which indicates how much the statement applied to you over the past 6 months.

There are no right or wrong answers. Do not spend too much time on any statement. The rating scale is as follows:

\begin{tabular}{ccccc}
\hline Once a week & Once a Month & Every few months & Less often & Don't' know \\
$\bigcirc$ & 0 & 0 & 0 & $\bigcirc$ \\
\hline
\end{tabular}

4. In the past 6 months, how often did you use the Internet to look for health or medical information for yourself?

5. In the past 6 months, how often did you use the Internet to look for health or medical information for someone else?

6. In the past 6 months, how often did you talk to a doctor, nurse, or other health professional about any kind of health information you have gotten from the Internet?

7. "Some people notice information about health on the Internet, even when they are not trying to find out about a health concern they have or someone in the family has." In the past 6 months, how often did you read such health information on the Internet unintentionally? 
Please read each statement carefully and choose one of the numbers from 0, 1, 2, 3 which indicates how much the statement applied to you.

There are no right or wrong answers. Do not spend too much time on any statement.

The rating scale is as follows:

\begin{tabular}{cccc}
\hline A lot & Some & A little & Not at all \\
$\bigcirc$ & $\bigcirc$ & $\bigcirc$ & $\bigcirc$ \\
\hline
\end{tabular}

8. In general, how much would you trust information about health or medical topics on the Internet?

9. How much attention do you pay to information about health or medical topics on the Internet?

10. In the last months, how often did you use your "native language" to search health related information on line instead of using English? 


\section{Appendix D}

\section{The Cross-Cultural Loss Scale (CCLS)}

\section{Instructions:}

People experience losses when they are in a different country, such as access to food from back home, the ability to handle daily tasks in the new environment, and a sense of connectedness with others.

Please rate the level each item below describes your situation based on comparing your experiences back in your home country with now living in this new country.

1. Not at all

2. Slightly

3. Moderately

4. Strongly

5. Completely

"Compared with your experiences back in your home country, NOW living in this new country you ..."

\begin{tabular}{llllll}
\hline 1. have less in-person access to family members in your home country & 1 & 2 & 3 & 4 & 5 \\
\hline 2. have less access to welfare (e.g., health care, benefits) for citizens & 1 & 2 & 3 & 4 & 5 \\
3. experience more restrictions as a foreigner & 1 & 2 & 3 & 4 & 5 \\
4. have fewer opportunities for intimate relationships & 1 & 2 & 3 & 4 & 5 \\
5. have less knowledge of the resources available in your environment & 1 & 2 & 3 & 4 & 5 \\
6. have a more difficult time fitting in with others & 1 & 2 & 3 & 4 & 5 \\
7. have less access to the cultural environment of home & 1 & 2 & 3 & 4 & 5 \\
8. have less access to entertainment from your home country & 1 & 2 & 3 & 4 & 5 \\
9. have less access to food from your country & 1 & 2 & 3 & 4 & 5 \\
10. sense a loss of civil rights (e.g., employment, vote) & 1 & 2 & 3 & 4 & 5 \\
11. feel less connected to others around you & 1 & 2 & 3 & 4 & 5 \\
12. are less certain about how to behave appropriately in daily life & 1 & 2 & 3 & 4 & 5 \\
13. have to deal with additional requirements to stay in this new country & 1 & 2 & 3 & 4 & 5 \\
14. feel less engaged to daily topics in your surrounding & 1 & 2 & 3 & 4 & 5 \\
\hline
\end{tabular}




\section{Appendix E}

The Satisfaction with Life Scale (SWLS)

\section{Directions:}

Below are five statements that you may agree or disagree with. Using the $1-7$ scale below, indicate your agreement with each item by placing the appropriate number on the line preceding that item.

Please be open and honest in your responding.

$7=$ Strongly agree

$6=$ Agree

$5=$ Slightly agree

$4=$ Neither agree nor disagree

3 = Slightly disagree

$2=$ Disagree

$1=$ Strongly disagree

\section{In most ways my life is close to my ideal.}

3 I am satisfied with my life.

4 So far I have gotten the important things I want in life.

5 If I could live my life over, I would change almost nothing. 


\section{Appendix F}

\section{Demographic Questionnaire}

1. Date of Birth : ${ }_{-} I_{-} I_{-}{ }_{-}(\mathrm{mm} / \mathrm{dd} / \mathrm{yyyy})$

2. Gender :
○ Female
○ Male

3. What is your marital status?
- Single, never married
- Married or domestic partnership
- Widowed
- Divorced
- Separated
- Prefer not to answer

4. What is the highest degree or level of school you have completed?
- Some high school, no diploma
- High school graduate, diploma or the equivalent (for example: GED)
- Some college credit, no degree
- Trade/technical/vocational training
- Associate degree
- Bachelor's degree
- Master's degree
- Professional degree
- Doctorate degree

5. Degree pursuing
○ Undergraduate
- Master
- Doctoral
- Non-Degree Seeking
$\circ$ Others

6. What is your current official enrollment status: 
7. What is the highest TOEFL Score you got?

○ Reading Section : (Score of: 0-30)

- Listening Section : (Score of: 0-30)

- Speaking Section: (Score of: 0-30)

○ Writing Section : (Score of: 0-30)

- Total TOEFL Score : (Score of:0-120)

8. What is your nationality?

9. Have you ever been to the U.S.?

10. Which State are you going to stay for study?

11. How long did you stay in the U.S.?

12. Do you have any health care coverage plan (please do not include dental or vision plans)?

13. How much is your health insurance's premium per year (please do not include dental or vision plans)?

14. In the last 6 months, not counting the times you went to an emergency room, how many times did you go to a doctor's office or clinic to get health care for yourself?
- None
- 1 time
○ 2
○ 3
○ 4
○ $5-9$
○ 10 or more 
15. How many times did go to an emergency room, in the last 6 months?
○ None
○ 1 time
$\circ 2$
$\circ 3$
○ 4
○ $5-9$
○ 10 or more

16. Please indicate if you have one of the following electronic devices?
○ Laptop
- Tablet
- Smartphone
○ Cell Phone

17. Where do you use the Internet from most often?
○ Home
○ Work
- School
- A public library
- A community center
- Someone else's house
- Coffee shop
- Others
- Don't know

18. When you use the Internet at home, do you mainly access it through...
- A regular dial-up telephone line (the normal telephone line)
- Broadband such as DSL, cable or FiOS
- A cellular network (i.e., 3G, 4G or LTE)
- Others
○ Don’t know 


\section{Appendix G}

\section{Research Participation Informed Consent}

IRB \#: 2004867

Campus IRB Approved Date: 02/22/2016

IRB Expiration Date: 02/22/2017

\section{University of Missouri Department of Educational, School, and Counseling Psychology}

Principal Investigator: Chih-Chun Chuang, M.Ed.

Research Study: Effects of Health Information Seeking Behaviors on Anxiety, and Loss among East Asian International Students

Dear Students,

You are invited to participate in a research study. The purpose of the study is to explore factors associated to health information seeking behaviors among East Asian international students in the United States.

In order to participate in the study, you must meet the following requirements:

(1) at least aged 18 or above.

(2) have a valid F-1 or J-1 visa status and already enrolled in a U.S. higher educational institution before Fall 2015

(3) originally from one of the following countries: China, Japan, Korea or Taiwan.

This study is conducted by Chih-Chun Chuang, who is a doctoral student in Health Education and Promotion in the Department of Educational, School and Counseling Psychology at the University of Missouri, Columbia, MO. This study has been approved by the Institutional Review Board of University of Missouri.

\section{RISKS AND BENEFITS:}

No more than minimal risks are anticipated with this study. Such risks may include fatigue, confusion, or mild discomfort when thinking about your career exploration and development. After the completion of the survey, you will have an opportunity to be entered There are no assured benefits from participating in this study. 


\section{DATA STORAGE TO PROTECT CONFIDENTIALITY:}

Your responses in this study will be private and anonymous. All data will be kept confidential and will only be reported in a conglomerate format (only reporting combined results and never reporting individual results). All questionnaires will be concealed, and no one other than then Primary Investigator and his Faculty Sponsor will have access to them. The data collected will be stored in the HIPPA-compliant, Qualtrics-secure database until it has been deleted by the Primary Investigator.

\section{TIME INVOLVEMENT:}

Your participation will take approximately 15-25 minutes.

\section{HOW WILL RESULTS BE USED:}

The results from this study may be presented at conferences, meetings, articles, or used for educational purposes.

\section{PARTICIPANT'S RIGHTS}

I have read the Research Description above and understand that my participation in this study is completely voluntary.

I may refuse to participate or withdraw from this study at any time without jeopardy to future medical care, employment, student status, or other entitlements.

The researcher may withdraw me from the research at his/her professional discretion.

If, during the course of this study, significant new information that has been developed has become available which may relate to my willingness to continue to participate, the investigator will provide this information to me.

Any information derived from this research project that personally identifies me will not be voluntarily released or disclosed without my separate content, except as specifically required by law.

If at any time I have questions regarding the research or my participation, I can contact the investigator, Chih-Chun Chuang (ccgkf@ mail.missouri.edu) or the Faculty Sponsor, Dr. Alex Waigandt (WaigandtA@ missouri.edu),who will answer my questions.

If at any time I have comments, or concerns regarding the conduct of the research or questions about my rights as a research subject, I should contact the University of Missouri Institutional Review Board/IRB. The phone number for the IRB is 573-8823181. Or I can write to the IRB at MU Institutional Review Board, Office of Research, University of Missouri, 190 Galena Hall DC074, University of Missouri, Columbia, MO 65212. For my personal records, I should print a copy of the Research Description and this Participant's Rights document. 
I should receive a copy of the Research Description and Participant's Rights document. By checking the box below and clicking "Next", I agree to participate in this study. Yes. I have read and understand the above, and I agree to participate in this study. No. I have read and understand the above, and I do not agree to participate in this study. 


\section{VITA}

Chih-Chun "Gene" Chuang was born in Changhwa, Taiwan on December $16^{\text {th }}, 1978$. He grew up in Nantou, Taiwan. He earned his Bachelor's of Science in Medical Sociology and Social Work from Kaohsiung Medical University in Kaohsiung, Taiwan. He completed his first Master's of Education in Adult and Continuing Education in 2006 from National Taiwan Normal University in Taipei, Taiwan and received his second Master's of Education in Health Education and Promotion from University of Missouri, Columbia, Missouri in December 2008. He will complete his Doctorate of Philosophy in Health Education and Promotion from the University of Missouri in July 2017. 